\title{
AFINIDADES MESOAMERICANAS DEL MITO TALAMANQUEÑO DE LOS DIOSES DE LAS TORMENTAS
}

\author{
Adolfo Constenla Umaña \\ Francisco Pereira Mora
}

\begin{abstract}
In this article I argue that the myth of the Sèrrkë, the Talamancan gods of the winds and storms, is actually a manifestation of the well known theme of the hero brothers, and that the detailed similarities with the version found in the Popol Vuh are an indication of its diffusion from the Mesoamerican Culture Area. The text of the myth, together with both literal and free translations, is included.
\end{abstract}

\section{Introducción}

El mito de los dioses de los vientos y las tormentas (bribri sềrkë, a veces pluralizado sềrképa) ha sido considerado por Guevara (1986: 128) como probablemente el más popular entre bribris y cabécares. El mismo autor (ibidem: 100) ha señalado que en la mitología talamanqueña parecen combinarse elementos de dos tradiciones: la mesoamericana y la sudamericana del tipo de las áreas del Orinoco y el Amazonas. A la primera se vincularían (ibidem) "los mitos del ciclo cosmogónico que explican el origen integral del universo" los cuales recuerdan "de manera llamativa las mitologías de pueblos netamente mesoamericanos como los quichés (Popol Vuh)"; a la segunda, los mitos que denomina "fragmentarios", es decir, "aquellos que se refieren a una creación independiente de las distintas cosas". Además (ibidem 103-8), ha indicado algunos de los temas y personajes de la mitología talamanqueña que consideró de tipo mesoamericano (entre los cuales no incluye a los dioses de las tormentas), eso sí, sin llegar a una decisión por lo que atañe a si las semejanzas fueron producto de difusión o no.

En este artículo me propongo argumentar en favor de la idea de que el mito de los dioses de las tormentas presenta rasgos que no sólo son indicios de algún tipo de coincidencia con Mesoamérica, sino, concretamente, de influencia de dicha área cultural sobre los talamanqueños. Las referencias, en este caso, se harán a una versión bribri recogida a instancias mias en 1976 por mi informante Francisco Pereira Mora a su tío Juan Pereira, suquia (chamán) originario de Alto Urén , entonces residente de Boca de Urén y ya fallecido (1982). Pereira Mora, publicó previamente, en 1983, una versión suya del mismo texto; no obstante, en vista de que varios detalles importantes de la narración de su tío quedaron excluidos, he considerado preferible publicar, como apéndice de este estudio, esta última. La transcripción -hecha con el alfabeto práctico bribri establecido por Jack Wison y el autor de este artículo, que se presenta, por ejemplo, en Margery Peña (1982)- es del señor Pereira Mora, quien la hizo en 1976 (la grabación se extravió). La presentación del texto en líneas, con el fin de resaltar recursos formales como el paralelismo, es mía. La traducción también lo es, si bien en todo momento consulté al señor Feliciano Elizondo Figueroa, informante bribri del Departamento de Lingüística de la Universidad de Costa Rica, a quien mucho agradezco su colaboración.

\section{Argumento de la versión empleada del mito de los dioses de las tormentas}

El texto se inicia con una breve caracterización. Los dioses, dieciséis hermanos, nacieron en este mundo (el universo bribri incluye, además del mundo habitado, actualmente, por los humanos, otros varios colocados tanto en niveles superiores como inferiores). El menor tenía características 
especiales: era velludo y era el más fiero. Desde su infancia la diversión de estos personajes era abrir zanjas (como cauces de ríos) y jugar con bolas (literalmente 'frutos de árbol', bribri kàl wö: kàl 'árbol', wồ 'fruto').

Hecha esta presentación, se entra en lo que podría considerarse como la primera parte de sus aventuras. Sibô, dios principal del panteón talamanqueño y creador de los indígenas, persuade a los dioses de las tormentas a visitar el lugar que queda debajo de donde nace el sol. Estos hacen su viaje, primero caminando hasta la orilla del mar, luego por el mar sobre el lomo de un hombre-lagarto al que llaman 'tío materno' (bribri naù ), luego por su lugar de destino (parte del viaje sobre la cual no se da ningún detalle) y , luego, de vuelta. Entre tanto, su madre ha sido matada por su propio padre, esto es, por el abuelo materno de ellos. Este devoró el cuerpo y dejó la cabeza colgando dentro de una canastita en una de las vigas circulares de la parte superior de la casa.

Cuando regresan, no advierten la ausencia de la madre (pues Sibồ había dispuesto que así sucediera) y vuelven a sus actividades habituales de abrir zanjas y jugar lanzando frutos ( $\mathrm{o}$ bolas). Un día en que jugaban dentro de la casa, la pelota va a caer al canasto en que estaba la cabeza de la madre. Uno de ellos sube a recogerla y la cabeza le revela lo sucedido. No obstante, él no le informa los otros sino hasta el momento en que se disponen a irse al lugar que habían conocido (que les había gustado). Entonces antes de marcharse matan y devoran al abuelo y dejan su cabeza junto con la de la madre en el cesto que cuelga del extremo superior de la casa.

La segunda parte sucede cuando se han establecido en el lugar debajo de donde nace el 'sol. Entonces uno de ellos, el octavo, avisa a sus hermanos que va a ir arriba , a casa de su abuelo paterno, Bakùbulu, a buscar novia y que si no regresa al cuarto día, será que sus enemigos lo han matado. En efecto, en la casa de su abuelo se encuentran dos tipos de seres malignos que lo matan, devoran parte de su carne y ponen otra a ahumar para conservarla: los its $Q^{\circ}$, que los bribris denominan en castellano tuleviejas (probablemente debido a que la tulevieja, personaje legendario de la tradición hispánica del área es una mujer greñuda y los bribris se imaginaban a sus its $Q^{\circ}$ con un aspecto semejante, según lo comprueba el disfraz hecho de hojas que usaban para representarlos, del cual se incluye una foto en Skinner 1920), y los kabêpa (singular kabê), término que los indígenas traducen con la palabra duendes (debido a que se trata de personajes de baja estatura, según lo indica su nombre, que significa 'niños, muchachitos').

Pasados los cuatro días, al ver que no regresa, uno de sus hermanos vaa buscarloy al llegar a la casa pasa, se sienta en una banca frente a su abuelo y pregunta por él. Bakủbulu le dice que, en efecto, sus enemigos lo mataron, pero que él no tiene culpa. Los duendes y tuleviejas (a los que seguiré mencionando por medio de estas traducciones indígenas), que se encuentran presentes se burlan de él y le ofrecen carne de la que tienen ahumada (los restos de su hermano). El se despide del abuelo diciéndole que a los cuatro días volverá con los demás y que la señal de su regreso será el sonido de sus tambores, que les tenga puesta una banca para ellos.

En efecto, a los cuatro días desde temprano se oyen retumbos y el cielo, a pesar de haber apenas amanecido se oscurece. Los quince hermanos se aproximan. El menor lleva en su mano un bastón que clava en el suelo produciendo los retumbos y cuando llegan no entra en la casa, sino que se dirige a un cerro situado detrás de ella en el que clava cuatro veces su bastón (que, según Guevara 1986: 128,no es sino el cordón umbilical de Sibồ ), estremeciéndolo de tal modo que pareciera que se elevara en el aire. Bakúbulu tiene la banca dispuesta para ellos, frente a otras en las que están sentados duendes y tuleviejas. Cuando se sientan, aquellos seres malignos intentan arrastrarlos hacia sí succionando, pero apenas logran moverlos un poquito. Entonces los hermanos se lanzan sobre ellos y los capturan y amarran. Entre tanto el menor con sus bastonazos estremece de tal manera el terreno que la casa pareciera que se elevara en el aire. Bakùbulu espantado, les ofrece todas sus riquezas para que no lo maten a él también. Los hermanos entonces se marchan arrastrando a los prisioneros y el botín en el viento.

\section{Algunos aspectos del sentido del mito de los dioses de los vientos y las tormentas en el pen- samiento bribri}

Para los bribris, este mundo es uno de varios, situados en niveles superiores unos, en inferiores 
otros. Sibò̀ escogió este mundo para establecer su casa y, dentro de ella, a la humanidad. Por supuesto, el hacer esto conllevó un proceso de mejoramiento u ortogénesis, toda una serie de cambios, entre ellos enviar a otros mundos (por medio de persuasión o expulsión) a la multitud de seres peligrosos que lo poblaban y que hubieran acabado fácilmente con la humanidad. El mito que nos ocupa trata de una de estas acciones (y, en consecuencia, habría que considerarlo dentro del ciclo dedicado, de acuerdo con Guevara, a la explicación del origen integral del universo): el persuadir a los dioses de las tormentas a ir a habitar el mudo situado debajo de donde nace el sol (llamado Nòpàtkuö o Nèpàryök en bribri) consiguiendo al mismo tiempo el desalojo de los duendes y tuleviejas. A partir de ese momento, los dioses de las tormentas, gracias a la enemistad establecida entre ellos y aquellos seres malignos, se encargan de perseguirlos y destruirlos (devorándolos) cuando se escapan del inframundo mencionado para venir a hacer daño a la humanidad. Esta función también la cumplen con respecto a otros monstruos, los jaguares de agua (dinamu ), que también se encuentran confinados en el Nòpàtkuö.

Por otra parte, en el caso de los talamanqueños se cumplen totalmente las afirmaciones de Eliade (1976: 135, nota 1) según las cuales (a) la creación o cosmogonía, aunque sea un hecho de un pasado remoto y su principal actor (o sus principales actores) se hayan retirado (como en el caso de Sibồ, que concluida su obra abandonó la tierra y se fue al cielo), "sigue sirviendo como el modelo ejemplar de todo acto de "creación" humana" y (b) el mito (ibidem : 18) establece un modelo universal de conducta. El narrador concluye la versión tomada en cuenta en este caso señalando que el conflicto entre los dioses de las tormentas y los duendes y tuleviejas es la razón por la cual los hombres entran en disputas y llegan incluso a matarse por las mujeres. En vista de que entre los bribris y cabécares (cuya adscripción clánica es matrilineal) el cónyuge idealmente era un primo o prima cruzado perteneciente al clan paterno (un hijo o hija de la hermana del padre), los duendes $\mathrm{y}$ las tuleviejas, entre los cuales el octavo Sềrkë fue a buscar su pareja, resultan ser parientes por afinidad y línea paterna de ellos, así como lo habría sido también el abuelo materno que mató a la madre de los
Sềrke̊pa (su propia hija). Esto es de gran interés, porque refleja tensiones entre los dos grupos entre los que se da la relación , caracterizándose el clan paterno como hostil y poniendo la empatía del lado del clan materno (aquel a que pertenece el individuo). La distinta actitud hacia los miembros del mismo clan y del clan aliado se advierte en el hecho de que los hermanos castigan a su abuelo materno y a los duendes y las tuleviejas (miembros del clan aliado todos ellos) con la muerte, en tanto aceptan una compensación material y dejan con vida al abuelo paterno (miembro, de acuerdo con lo explicado del clan propio). Este hecho ha sido notado claramente por Bozzoli (1979 : 151 y siguientes) a quien se debe un detallado análisis del mito en cuestión (1983 : 128 y siguientes) en el que muestra cómo éste y otros relacionados tienen que ver con la configuración del universo según este es percibido desde la experiencia bribri en Talamanca. En la primera de las obras mencionadas, postula como un rasgo estructural básico del sistema de creencias talamanqueño una dicotomía entre lo de abajo y lo de arriba que abarca varias oposiciones entre las cuales está la que se da entre el clan propio (el materno) y el clan paterno. Como hemos visto, los dioses de las tormentas, que han escogido como morada un mundo situado, al parecer al mismo nivel que el de los humanos, entran en conflicto con los duendes y las tuleviejas, que habitaban con Bakùbulu en las regiones más elevadas de la cordillera.

\section{Los dioses del viento y las tormentas como representantes de los "hermanos héroes" en la mitología bribri}

En la segunda obra (1983), Bozzoli, al tratar aspectos del mito de los dioses de las tormentas relacionados con la periodicidad estacional, señala que está relacionado con los tratados por LéviStrauss en la sexta parte y en el comienzo de la sétima de El origen de las maneras de mesa . La relación no sólo se da, sin embargo, en ese sentido, sino que tanto los protagonistas de algunos de dichos mitos como. los dioses de las tormentas bribris son manifestaciones de un tema de gran importancia en la tradición indígena americana: el de los "hermanos héroes". 


\subsection{El tema de los "hermanos héroes"}

En las mitologías de numerosos pueblos indígenas norteamericanos (Alexander 1964a: 295) se da como rasgo común la presencia de dos personajes llamados por los tratadistas "hermanos héroes" (heroe brothers) sobre los cuales se narran mitos que tienen muchos motivos en común con el bribride los dioses de las tormentas, como se notará en varios ejemplos que se dan a continuación.

Entre los cheroquíes, estos hermanos son los dioses de los truenos (the Thunderers ; ibidem : 62). Entre algunos pueblos de las Grandes Llanuras los hermanos son perseguidos por la cabeza de su madre (que había sido decapitada por el padre), uno de ellos es capturado por un mago del cual escapa, en tanto el otro perece a manos de dos monstruos acuáticos, pero luego es revivido por el primero (ibidem: 104). Entre los sálishes de Thompson River (ibidem: 1367) los hermanos son entusiastas del juego de lacrosse, uno de ellos es secuestrado por los hombreshormiga del inframundo, que se lo llevan a jugar con ellos, y el otro lo busca hasta que finalmente llegan a reunirse. Entre los navajos (ibidem :164-5) los hermanos viajan, por consejo del Viento, a la casa del Portador-del-Sol (situada a orillas de una gran extensión de agua) que, primero, trata de matarlos, pero que, viendo que no lo logra, termina por darles las armas (entre ellas "flechas de relámpago") que necesitan para acabar con los monstruos devoradores de hombres que infestaban el mundo.

En Mesoamérica, la manifestación más conocida del tema se encuentra en parte del primer libro del Popol Vuh y todo el segundo (Alexander 1964a : 137, 1964b : 159).

En esta obra, que tiene lugar en lo que Alexander (1964b: 168) llama la Edad de los Gigantes (antes de que surgiera el presente sol), se da una primera pareja de hermanos, Hun-Hunahpú y Vucub-Hunahpú, hijos de la diosa Ixmucané (identificada por Preuss, 1988: 7, como diosa lunar que determina el período lluvioso) diestros en el juego de pelota y en el uso de la cerbatana. El ruido de su juego llega hasta el inframundo, Xibalbá, cuyos príncipes, también aficionados a él, les envían una invitación a competir. Los hermanos se dirigen allá, donde al llegar, después de haber atravesado cuatro ríos, sufren engaños que los ponen en ridículo (se encuentran, primero, sobre las bancas a unos muñecos de palo a los que saludan pensando que se trata de los príncipes y luego se sientan en la banca que a ellos se les ofrece, que resulta ser una piedra al rojo vivo que les quema las posaderas) y no logran pasar una prueba a las que se los somete, por todo lo cual tienen que conformarse con ser sacrificados.

La cabeza de Hun-Hunahpú es colocada en un árbol, donde toma el aspecto de fruto del mismo. Una doncella, Ixquic, se aproxima al árbol desde el que le habla la cabeza que, además, le deja caer saliva en la mano con lo cual la deja embarazada. Los príncipes del inframundo quieren matarla, pero ella logra escapar y llegar a la casa de Ixmucané, donde después de pasar una prueba, es reconocida como nuera y da a luz a una nueva pareja de héroes: Hunahpú e Ixbalanqué. La abuela es hostil, al principio, con ellos y los maltrata, debido a su preferencia por otra pareja de hijos que ya tenía HunHunahpú antes de marcharse. Hunahpú e Ixbalanqué, cuya diversión era tirar con la cerbatana todos los días, logran deshacerse de sus medios hermanos convirtiéndolos en monos y pasar una prueba a la que los somete la abuela. La prueba, consistente en hacer una abra, los obliga a enfrentarse a los animales del bosque, que de noche hacen crecer de nuevo la vegetación. En este enfrentamiento logran capturar al ratón, por cuyo medio encuentran la pelota, el aro, los guantes y los cueros con que su padre y su tío, en otro tiempo, habían jugado y que habían sido colgados del techo de la casa. En posesión de estos utensilios, los hermanos se aficionan al juego de pelota tanto como los héroes desaparecidos.

El ruido producido por el juego de nuevo alerta a los príncipes del inframundo que envían mensajeros a retarlos. Los nuevos héroes averiguan la existencia de los muñecos de palo y de la banca de piedra caliente y, en consencuencia, evitan quedar en ridículo como su padre y su tío. Son sometidos a varias pruebas de las que logran salir exitosos, excepto de la última, que era dormir en la casa de los murciélagos, cuyo dueño, un murciélago enorme, se esperaba que los matara. Los hermanos duermen metidos en sus cerbatanas, con lo cual hubieran evitado todo peligro. Pero Hunahpú, queriendo ver si ya ha amanecido, asoma la cabeza y es decapitado. Los enemigos, muy alegres, encuentran la cabeza y la cuelgan sobre su cancha para juego de pelota. 
Ixbalanqué, con la ayuda de los animales, logra hacer una cabeza falsa que le coloca a Hunahpú y lo revive. Entonces van a jugar contra los señores del inframundo y , en una jugada, Ixbalanqué lanza la pelota fuera de la cancha y, mientras aquellos corren a buscarla, recupera la cabeza de su hermano y se la coloca.

Sin importar que los hermanos hayan pasado todas las pruebas, los señores del inframundo los condenan a muerte en una pira. Los héroes suben sin temor, pues ya han tomado la precaución de que los encargados de deshacerse de sus huesos los muelan y los echen al río. En efecto, esto se hace así y, del polvo lanzado al agua, renacen, adoptando la apariencia de dos mendigos que realizan actos de magia consistentes en destruir cualquier cosa o despedazar a cualquier persona o animal y, luego, devolver el objeto de su acto a la condición original. Los dos señores principales del inframundo los llaman y, entusiasmados por su acto, piden ser, ellos también, despedazados y resucitados. Los hermanos hacen lo primero, pero no los segundo. Los demás señores huyen entonces espantados, pero también son destruidos, con la excepción de uno que se entregó voluntariamente y pidió clemencia. Después de condenar a Xibalbá a la ruina y la esclavitud, los hermanos intentan resucitar a su padre y a su tío, pero no lo logran y , entonces, para honrarlos los envían al cielo como el sol y la luna.

Todo lo anterior sucede en el segundo libro. A finales del primero, se cuentan los enfrentamientos de Hunahpú e Ixbalanqué con tres gigantes que pretendían ser los dueños de la tierra, parte de la preparación del mundo para la creación de los hombres de maíz, como lo había sido el cataclismo que acabó con los hombres de palo.

La epopeya de Hunahpú e Ixbalanqué no es el único ejemplo mesoamericano. Entre los pipiles del Salvador, en mi opinión, los mitos sobre los Muchachos de la Lluvia (Schultze-Jena 1977: 29 y siguientes) presentan varios motivos que los caracterizan como versión del tema de los hermanos héroes, según se podrá apreciar del resumen de parte de los textos que tratan sobre su origen y aventuras que doy a continuación.

Un hombre, al que le dicen que su mujer lo abandona de noche para traicionarlo, la espía y se da cuenta de que la cabeza y las extremidades se desprenden y se van, quedando sólo el tronco.Siguiendo consejos, unta de sal el tronco y entonces las partes no se pueden unir. La cabeza, entonces, se pega al cuerpo del hombre y así sobrevive hasta que él, por medio de un truco, se libera de ella. Donde queda la cabeza surge un árbol y de las semillas de su fruto nacen los Muchachos de la Lluvia (veinte, según se desprende de otro de los mitos recogidos por Schultze-Jena). Estos quedan al cuidado de la abuela paterna, cuyo amante -un gigante- se come la comida que ellos obtienen haciéndolos pasar hambre hasta que ellos lo matan y se van a vivir a otro lugar. Allí se dan cuenta de que, dentro de una montaña, está el maíz y, para apropiarse de él, intentan partirla con rayos, empresa en la que triunfa el menor de todos, que es el más habil y el que produce los rayos más poderosos.

En Sudamérica, el tema de los "hermanos héroes" no parece haber revestido una importancia comparable a la que tuvo en Norteamérica (tal es la impresión que dan los tratados sobre las respectivas mitologías, aun los escritos por un mismo autor, como Alexander 1964a y 1964b), aunque se dan versiones en que dichos personajes juegan también papeles básicos en las transformaciones del mundo para dotarlo de su configuración definitiva. Además, a partir de las referencias observadas, como los casos incluidos por Lévy-Strauss en sus Mitológicas (1972a : 112, 287 8; 1972b: 27-8,99-100,102-4, 181-2, 183, 303,3301; 1979: 136-8) pareciera que en esta área no se los relaciona con los truenos, vientos y tormentas. $\mathrm{La}$ identificación aparentemente predominante es con el sol y la luna (como sucede en el Popol Vuh con la primera pareja de hermanos), pero también se vinculan con ciertas constelaciones o con el arcoiris. De hecho, entre grupos más próximos geográficamente a los bribris y a los cabécares a los que se han recogido manifestaciones del tema, los bocotaes y moveres del oeste de Panamá (Margery Peña 1989), la identificación se establece con el sol y la luna .

\subsection{Motivos del mito de los dioses de las tormen- tas presentes en otras versiones del tema de los "hermanos héroes"}

Los hermanos héroes aparecen ligados en Norteamérica y Mesoamérica, en general, a los fenómenos atmosféricos como la lluvia, el viento, 
los truenos y los rayos. Los dioses talamanqueños de las tormentas y los vientos son además hijos del dios Trueno marido de la diosa Lluvia o de su hermana, según las versiones (cf. Guevara $1986: 128$ y siguientes).

Los hermanos héroes en Norteamérica son dos en las versiones que conozco, pero en Mesoamérica se multiplican. En el Popol Vuh hay dos parejas de héroes y los Muchachitos de la Lluvia pipiles son muchos, probablemente veinte, como se señaló antes. En el caso de los talamanqueños son dieciséis (múltiplo del número mágico bribri y cabécar: cuatro).

En Norteamérica, el mayor de los hermanos es el mejor dotado desde el punto de vista físico, en tanto el menor tiene habilidades mágicas (cf. Alexander 1964a: 295). En Mesoamérica las características especiales parecen concentrarse en el menor. Estoes totalmente evidente en el caso de los Muchachitos de la Lluvia pipiles, pero también se manifiesta en el caso del Popol Vuh, en que es Ixbalanqué, el segundo hermano, el que sobrevive a la prueba de la Casa de los Murciélagos y el que se las ingenia para revivir a Hunahpú, el primero.El menor de los Sềrkêpa es, como ya se ha señalado el que presenta rasgos más definidos y llamativos.

Tanto en Norteamérica como en Mesoamérica, los hermanos aparecen en algunas versiones como aficionados a un juego en el que se usan bolas: el lacrosse entre los sálishes, el tlachtli o juego de pelota entre los mayas. Los protagonistas del mito talamanqueño tienen como un pasatiempo favorito el jugar con bolas.

Tanto en Norteamérica (por ejemplo, en el caso de los navajos) como en Mesoamérica (en el Popol Vuh) se dan versiones en que los hermanos participan en la adecuación de la tierra para la humanidad por medio de la eliminación de seres extraordinarios nocivos, como sucede en el mito talamanqueño.

En general, las distintas versiones hacen referencia a algún tipo de viaje que, con frecuencia, es a otro mundo separado de éste por ríos o por un mar. En varias versiones, también, el motivo del viaje es que uno de los héroes es secuestrado o privado de la vida por seres extraordinarios y el otro o los otros viajan a rescatarlo o vengarlo (en el caso del Popol Vuh, los héroes de una generación son destruidos y los que van a vengarlos son los de la siguiente). Estos rasgos se presentan también en el mito talamanqueño de los dioses de las tormentas.

En varias versiones, también, se da la decapitación de la madre de los héroes o de uno de ellos. En versiones norteamericanas y en la pipil, el padre es responsable de la decapitación de la madre. En la versión bribri comentada, el abuelo materno (miembro del clan paterno) es quien lleva a cabo esta acción. La cabeza en todos estos casos se mantiene con vida para tener algún tipo de participación en los acontecimientos venideros.

Además de las coincidencias anteriores, se pueden señalar otras, pero que se dan,exclusivamente al parecer, con el Popol Vuh ( las versiones norteamericanas las conozco sólo por medio de resúmenes, de manera que no puedo estar seguro de que en ellas no se hayan omitido detalles):

(a) Tanto en el Popol Vuh como en el mito talamanqueño hay objetos que se esconden colgándolos en un lugar elevado de la casa (en el mito bribri la cabeza de la madre, en el texto quiché la pelota y otros utensilios del juego que habían pertenecido a Hun-Hunahpú y a Vucub-Hunahpú) y que luego son descubiertos por los hermanos héroes de manera accidental.

(b) En ambos textos los seres malignos (del inframundo en un caso, de las alturas en otro) tienen una actitud burlona para con los héroes en el momento en que estos llegan por primera vez.

(c) En ambos textos se prepara una banca para los héroes. En el Popol Vuh se trata de la banca de piedra caliente destinada a quemarles las posaderas, en el mito de los Sềrképa la banca en la que los héroes se sientan a enfrentar a duendes y tuleviejas. En ambos casos la banca tiene que ver con una prueba a la que son sometidos lós héroes por los seres malignos.

(ch) Ambos textos concluyen la aventura con el regreso de los héroes a su lugar después de haber dejado a sus enemigos en la ruina. El Popol Vuh (1965: 100) dice en referencia a los de Xibalbá: “Así fue, pues, la pérdida de su grandeza y la decadencia de su imperio"; la traducción de la versión del mito de los dioses de las tormentas publicada por Francisco Pereira (1983: 21) dice, a su vez: "Al irse vieron que la casa de Bakùbulu estaba totalmente destrozada, comprendieron que lo dejaban en completa ruina". 
4. El juego de pelota: rasgo mesoamericano inconfundible del mito de los dioses de las tormentas

Los rasgos comentados, en general, prueban que el mito talamanqueño de los dioses de las tormentas es una versión del tema de los "hermanos héroes"; pero, además, en vista de lo detallado de las coincidencias con el Popol Vuh, dan indicios muy fuertes de que sea una versión que, de manerá directa o indirecta, llegara a los bribris desde Mesoamérica.

De ellos hay uno, que comentaré de manera particular a continuación, que constituye el indicio más decisivo de influencia mesoamericana. Los juegos a los que se dedicaban los dioses de las tormentas consistían en cavar zanjas como cauces de ríos y jugar con bolas. La asociación entre estas dos actividades, adquiere sentido si pensamos que las zanjas aludidas representan los patios rectangulares y rodeados a los lados por muros y terraplenes en los que se practicaba el tlachtli o juego de pelota mesoamericano. No existen hasta el momento, indicios, en Talamanca o en regiones vecinas inmediatas, de la existencia de patios de juego de pelota, de modo que los bribris probablemente no llegaron a conocer dicho juego de manera directa, sino por referencias, lo cual explicaría la imprecisión con que se alude a él. El patio de juego de pelota más cercano a Talamanca parece haber estadoen Panamá, pues de acuerdo con Doris Stone (1976: 150), en la Península de Azuero, un conquistador observó la existencia de uno parecido a los que había visto en Haití (Stone, con base en esta y otras razones, piensa en influencias arahuacas). Bien pudiera suceder que llegaran hasta los bribris noticias de la existencia del juego en dicha área de Panamá, pues actualmente hay bastante consenso entre los investigadores de que en la Baja Centroamérica se daba una cadena de relaciones entre pueblos vecinos que permitía la difusión de técnicas e ideas en todas direcciones (cf. Bray $1985: 308-9$ ). No obstante, parece claro que los más probables trasmisores de estas referencias habrian sido otros de los pobladores del Valle de Talamanca en el momento del contacto con los españoles, los indios zeguas o siguas (Fernández Guardia 1975: 148), que los conquistadores identificaron como hablantes de lengua mejicana (náhuatl) y por los que llamaron al Valle "Valle de Duy y
Mejicanos" (la palabra bribri Dúi designa todavía el territorio entre el Sixaola y el Changuinola). Sobre ellos, lo más habitual ha sido pensar que fueran una colonia de comerciantes y guerreros aztecas (Stone ibidem: 144), si también se ha pensado que pudieran ser elementos de más antiguo asentamiento en Centroamérica como los pipiles de El Salvador o los nicaraos.

\section{APENDICE}

\section{Versión del mito de los dioses de las tormentas por el suquia don Juan Pereira}

El texto que se ofrece a continuación es una buena muestra de la narración tradicional bribri tal y como ha sido caracterizada desde el punto de vista del contenido y de las circunstancias sociales por Bozzoli (1979: 28-9) y Pereira Mora (1983: 13). También lo es desde el punto de vista de la forma literaria, sobre la cual hasta el momento prácticamente no se ha dicho nada, razón por la cual haré algunas observaciones al respecto. Una de las primeras interrogantes que surgen a este último respecto es si dichas narraciones, desde el punto de vista de la teoría literaria occidental, pueden en algún sentido caracterizarse como textos en prosa o en verso. Cohen (1974:53) haafirmado respectode esta distinción lo siguiente:

Todo verso es "versus", o sea, retorno. Por oposición a la prosa ("prorsus") que avanza linealmente, el verso vuelve siempre sobre sí mismo.

Tomando la caracterización de Cohen, pero sin restringir el retorno a lo fonológico, para mí es un hecho bastante claro que los textos narrativos bribris, según los suelen producir los buenos narradores como don Juan Pereira, tendrían que considerarse como un tipo de versificación en que el recurso fundamental es el paralelismo, es decir (Lázaro Carreter 1962) la

Disposición del discurso de tal modo que se repitan en dos o más versos sucesivos, o en dos estrofas seguidas, un mismo pensamiento o dos pensamientos antitéticos...O bien, mantenimiento de una misma estructuraen dos o más frases seguidas... 
La lectura del texto permitirá apreciar la constante presencia de este rasgo que le da un caracter marcadamente rítmico, como en el siguiente ejemplo:

$$
\text { Ie' } r \text { icha, }
$$$$
\text { ie' } r \text { icha kồchi âmé, }
$$$$
\text { ie' } r \text { icha vaca muéwa a amé, }
$$$$
\text { ie' } r \text { icha sawi'jkuö âmé âmé, }
$$$$
\text { ie' } r \text { icha chò kalôwé, }
$$$$
\text { ie' tòn }
$$

470 e' ta ñẹ'e se'è wồ kề tsirineia

$$
\begin{aligned}
& \text { El, pues, } \\
& \text { entrega, pues cerdos, } \\
& \text { ata y entrega, pues, vacas, } \\
& \text { entrega y entrega, pues, telas, } \\
& \text { coge, pues, chompipes, } \\
& \text { paga su precio, } \\
& \text { y, entonces, ya no lo acosan más. }
\end{aligned}
$$

La transcripción de los textos narrativos de las literaturas indígenas costarricenses ha procedido hasta el momento a partir del a priori de que se trata de discursos en prosa, probablemente bajo la influencia de la concepción general de que los textos narrativos tradicionales de la cultura hispánica dominante (cuentos folclóricos y leyendas, por ejemplo) se dan en dicha forma. Mi propósito al darle al texto que nos ocupa la presentación de tipo verso es tratar de hacer evidentes recursos formales que en una de tipo prosa se ocultan. Por supuesto, mi intento es sólo una primera aproximación. Pudiera ser, por ejemplo, que existiera también algún tipo de organización estrófica que yo no haya percibido y no dudo que la división en líneas pueda en muchos casos modificarse logrando reflejar mejor la estructura rítmica creada por el arte del narrador.

Los otros recursos de la narración tradicional bribri a los que haré referencia aqui son el uso de ideófonos y lo que denominaré "perfectivo prospectivo histórico".

Los ideófonos son elementos léxicos de la clase correspondiente a los adverbios de modo y los adjetivos castellanos que se caracterizan frente a otros modificadores con funciones semejantes por su carácter marcadamente motivado, muy frecuentemente onomatopéyico o fonosimbólico. En castella- no existen elementos de esta naturaleza, como cataplún para describir el sonido de la caída de un objeto grande al agua, pero parecieran ser relativamente poco abundantes y estar restringidos a los estilos más coloquiales, de modo que se los excluye por completo de la literatura escrita. En bribri, en cambio, estos elementos se dan en gran número y son un recurso muy importante de la buena técnica narrativa que no desmerece su inclusión en los textos de la lengua de estilo más elevado. Los ideófonos dan una contribución de especial importancia al componente descriptivo de las narraciones, como sucede, por ejemplo en muchas literaturas nativas africanas. Como señala Noss en su estudio sobre la descripcción en la narración gbaya:

El ide 6 fono es una palabra descriptiva que, a diferencia del verbo (que meramente enuncia acción) y del adjetivo (que s6lo describe un elemento), crea emoción. Crea un cuadro; es sensual, permitiendo al que escucha identificar sensaciones, sonidos, colores, texturas, expresiones, movimientos o silencios por medio de sus propios sentidos. El ideófono es poético; es, en el sentido más puro, imaginería.

La vivacidad que da el ideófono a la narración se puede apreciar en el siguiente pasaje del texto que nos ocupa:

\section{àsir tkáa ie'pa wa púj, hacen que se venga un derrumbe púj, \\ ùùù àsir yềnàna. ùùù se desliza el derrumbe.}

Nótese la adecuación del vocalismo oscuro (u) de ambos ideófonos con el fenómeno del derrumbe en general y la del tono de cada uno de ellos con sus fases: un solo tono descendente en el primero (que representa el momento en que se desprende la tierra) y un tono alto prolongado en el segundo (que describe el deslizamiento continuo de la tierra).

Finalmente, denomino "prospectivo histórico" un uso de los tiempos verbales parecido al que se suele denominar presente histórico en lenguas como el castellano. En bribri existen dos tiempos aspectualmente perfectivos: uno, que actualmente prefiero denominar improspectivo, fundamentalmente referido a hechos acaecidos antes del inicio del día en que se está (el día bribri empieza y termina con las puestas de sol) y otro, el prospectivo, referido a los que han sucedido durante el día en que se está, 
suceden en el momento presente o sucederán en cualquier momento del futuro. En las narraciones, como ya fue notado por Schlabach y Levinsohn (1982: 80) el prospectivo predomina en la presentación de los hechos de primer plano, en tanto el improspectivo se emplea para hacer referencia a acontecimientos de segundo plano.

Para concluir esta introducción al texto, señalaré que mi traducción ha procurado ser fiel al tex to bribri (por ello, por ejemplo, he empleado sólo dos pronombres de segunda persona, uno de singular, 'tú', y otro de plural,'vosotros', pues la lengua no tiene distinciones del tipo 'tú'-o 'vos'-/'usted') lo cual implica entre otras cosas captar el tono solemne que tiene la narración en el original . Como ha señalado Bozzoli (ibidem : 29) los textos de este tipo emplean "un estilo serio de conversar... no uno vulgar". La elevación estilística de buena parte de los textos indígenas narrativos que se han publicado hasta el momento ha quedado anulada en las traducciones por diversas razones, entre las cuales una de las más frecuentes es el deberse aquéllas a informantes sin dominio del estilo castellano que corresponda mejor al empleado en el texto original en lengua indígena.

\section{Abreviaturas empleadas}

\section{FP: $\quad$ Francisco Pereira}

JP: Juan Pereira

ag posposición que indica el agente de las formas transitivas perfectivas negativas y el de verbos intransitivos cuando se emplean con dos actantes (como cuando dók ' 'llegar' se usa en forma transitiva con el significado de 'traer')

dim diminutivo

erg posposición que marca el caso ergativo

fin forma verbal infinitiva que expresa finalidad

impl,

imp2 flexiones imperfectivas, básicamente atemporales; la segunda, sin embargo se

emplea con mayor frecuencia que la otra en contextos de futuro y en referencia al presente $\mathrm{y}$ al pasado suele tener valor habitual

impro flexión perfectiva improspectiva

int flexión de grado intenso de los adjetivos y adverbios

lim limitativo ('sólo')

opt flexión optativa; se usa como imperativo en referencia al futuro y con el significado de 'decidir (hacer algo)' en referencia al pasado

perf flexión perfectiva sin marca temporal empleada con la negación

pot flexión de potencial (traduce tanto al futuro como al potencial del castellano)

pro flexión perfectiva prospectiva

rec pronombre recíproco

ref pronombre reflejo

rep flexión verbal que indica repetición de la acción o realización de una acción semejante a otra anterior

\section{Otras convenciones empleadas}

Los dos puntos al lado de una letra en el texto bribri indican un alargamiento expresivo del sonido correspondiente.

Las formas unidas por medio de guiones en la traducción literal corresponden a una sola palabra bribri En algunos casos ésta está integrada por una cadena de morfemas, pero en otros puede ser monomorfemática.

(todavía) flexión verbal equivalente al adverbio

castellano 'todavía'

flexión verbal equivalente al adverbio castellano 'ya' 
Texto bribri y traducción libre

FP: Bueno entonces ก̃e' yö i che este... ¿wè̀s Sềrkë añi buk...

- kabépa añi buk?

¿Ima i kièke...?

5 JP: '¿Bakùbulu?

FP: Bakùbulu ta.

E' apà kó ña, ¿wè̀s e' wámbalềné?

10

Mjḿ

Sèrkë tskìne íe dök,

Ká i ki Sềrkë tskìne.

JP: Sềrkë tskìne tsî:ralaralar í $\underline{e}$,

wè̀s alâttsítsi,

se' alâttsítsi,

kùna e e' kapë.

Ta icha ie'pa $r$ diböl ñalà bié, icha di âwí ñalà bié,

di' dió ñalà bié,

di' awí ñábale,

diố, diố, diố nábale,

ñábie ie' dör,

ie'pa tsî:r e' dör icha.

FP: Pero, ¿e'r yí alar?

JP: Icha e'...e' m...

FP: ¿O é e' tské Sibồ dör?

JP: E' tskík Sibồ dör.

30 FP: Ajá.

JP Sibồ $r$ e' tskík,

e' ajkà óritse

wák e' ñe’es irir icha. Icha...

FP: ¿ Sềrkë?

JP: Sè̀rkë.

FP: Mjmí.

JP: $\quad$ E' ta fié icha e' dör íma... se'...

e' dör ká ñè ká ñé bièke ,

ká m... ká ñalà i', dìböl ñalà bièke,

diböl ñala katèke,

wè̀s alâttsítsi tsîr tsîr

di' di' tsítsirala sé katè e’kapë.
FP: Bueno, entonces aquello que dije, este... ¿Cómo pelearon los Sềrkës...

o pelearon los duendes?

¿Cómo se llama...?

JP: ¿Bakùbulu ?

FP: Con Bakùbulu .

Cuéntame eso.

¿Cómo sucedió?

Eso fue, pues, primeramente,

cuando, pues...

cuando, pues, esos e... losSềrkës nacieron aquí.

Los Sềrkës nacieron aquí, en este lugar nacieron los Sèrrkës.

FP: Mjm.

JP: Los Sèr kës nacieron pequeñitos aquí, así como los niñitos,

los hijitos de las personas,

nacen.

$Y$, pues, ellos cavan barrancas, pues, cavan el cauce de aquel río, cavan el cauce de aquel río abajo, escarban el cauce de aquel río arriba, escarban aquél, aquél, aquél abajo, excavan ellos,

ellos, siendo pequeños, pues.

FP: $\quad$ Pero, ¿de quién eran hijos?

JP: $\quad$ Pues, ellos... ellos...

FP: ¿O no más los crea Sibồ ?

JP: Los creóSibồ .

FP: Ajá.

JP: Sibồ los creó,

mencionó su nombre,

de hecho así fue, pues. Pues...

FP: ¿Sè̀rkë ?

JP: Sèrkë.

FP: $\quad$ Mjm.

JP: $\quad Y$ entonces, pues, ellos este...personas...

ellos cavaban aquel terreno, aquel terreno, el terreno m... estas zanjas, cavaban barrancas, hacían barrancas así como los niñitos pequeños hacen ríos, esos ríos pequeñitos. 
E'r nè'e

ie'pa dé taíktaík,

ta nè'e ie'pa talárềme,

ta nẹ'e ie'pa dör pàryök bốyök

-e' r se' r i kie tö dabòn̈ éyök kị tèröl-.

E' ta i batà sạêeèala e' dör sulûë.

E' kalồ kö tă', e' bitsi' kö âr pôë.

FP: ¿E'r sì kua alà?

JP: Mjḿ.

FP: Ajá.

55 JP E' ta ñèe icha

kéwe ie'pa mí apàtke Sibồ $r$ ká sauk âwì dikì a icha.

FP: Ajá.

JP: Dìwö dikì a icha ie' ké,

ie' apàtkë icha Sibồ $r$;

Sibồ $\mathrm{r}$ ie’ apàtkë Dìwö âwì dikì a ká saunk:

“¡Ba yú ká sauk

tö is irir!"

FP: ¿Yì? ¿Nè'?

JP: I wébipa ñé.

FP: ¿Todos?

JP: E' apàtkë séka Sibồ $\mathrm{r}$ ká saunk,

tö: "¡Yùshka ká sauk

tö ìs ká dör".

70

Ie'pa mía ùùù

dé dayề dià a

ta dayề e'...ta wébala ñẹ' tkër icha...

FP: ¿Yì tkër?

JP: E' ema talók tër icha,

e' kie icha naù̀.

E' a i ché icha,

talók a i ché icha:

"iÀ naù icha,

sa mí ká saukk,

ña amútkö bö ulù ki."

FP Ajá.

JP: Ne'e icha ie'pa...

ie'pa ulù ñe',

talók tsìwö ki,

ie'pa ê' tuléka

e' tsémi talók ùùù

âméttsa di' awíshet.

FP: ¿II'pa mìn wâñerè̀?

JP: Mjmí, séka.

Mìk wốiá i dótkemạlẹ,
Ello fue, entonces,

que llegan a estar grandecitos

y entonces crecen no más,

$y$ entonces eran dos octenas

-lo que solemos decir dieciséis-.

$\mathrm{Y}$ el menor, muy delgadito, era muy fiero.

Tenía vello en las piernas,

crecía en su pecho abundante vello

FP: ¿Era hijo de blancos?

JP: Mjm.

FP: Ajá.

JP: Y entonces, pues, primero los envía Sibò

a conocer un lugar debajo de allá, pues.

FP: Ajá.

JP: Debajo del sol, pues, los manda, los envió, pues,Sibồ ;

Sibồ los envió allá debajo del sol a conocer:

"ild vosotros a conocer el lugar a ver cómo es!"

FP ¿A quién? ¿A aquellos?

JP: A aquellos hombres.

FP: ¿Todos?

JP: Los envía a todos Sibồ a conocer el lugar, ¡i d a conocer el lugar:

a ver cómo es!"

Ellos se van ùùù,

llegan al mar allá abajo

y en el mar... y estaba aquel hombre, pues..,

FP: ¿Quién estaba?

JP: Alli entonces estaba el lagarto, pues, a él lo llamaban ellos tío materno.

A él le dicen, pues,

al lagarto le dicen, pues:

“i Oh tio materno!, pues, nosotros vamos a conocer un lugar, pásanos en la balsa!"

FP: Ajá.

JP: Entonces, pues, a ellos...

a ellos que sobre la balsa aquella, sobre la espalda del lagarto, se suben, los lleva el lagarto ùùù, los deja al otro lado de las aguas.

FP: ¿Iban todos ellos?

JP: $\quad$ Mjm, todos.

Entonces, cuando ya se viene de nuevo 
talók tö i ché i a tö:

"Tkệk ya dờmale,

e' ta icha tkệk

ba kiémale icha :

"Ya tsúktkömale,

dồmale ie ".

Tkệk ie' démale.

E' dalé ie' mìnêa,

mìka e' dalé ñée ska ie' da,

100

Sè̀rkë amìwöla kata'wa i yé tö.

FP: ¿Sềrkë yé tö ?

JP: 'M'm̀. I alà... i alà kata'wa.

I alà bùsi kata'wa ie' $r$.

Icha mìka ie' mìnệa wö... wö...,

i alâr nê' pònemi e' dalé wa, i amì kótwa icha ie'r.

Kata'wa ie' $r$ icha,

wóki tkë'ka ie' dör bika' a aìes,

icha kájkệ aì,

kàl aké ki aíes

aí wồkachi ki,

ù sulế a bichi' ki icha.

FP: Mjḿ.

JP: Bichi' ki icha

FP: ¿Yì wóki tkë'ka ?

JP: Ne' i kata'wa,

$i$ alà katàwa $r$

e' wóki tkë'ka.

FP: ¿Pero yì r e' kata'wa?, perdón, ¿ Sè̀rkë ?

JP: I wô.... i wô... i wôkela, i wôkela. Sè̀rkë wôkela. ¿ Âna ma én a ?

FP: A, ¿ Sè̀rkë abuelo?

JP: Mjḿ. E'r icha i ami

be'r i saú, i a...

FP: ¿Së̀rkë ami kata'wa?

JP: Ámì kata'wa,

I alà bùsi kata'wa ie' dör.

130 FP: Ah, ya. Ajá.

JP: Entonces i alâr nễ déne

ta icha nẹ'e i alâr tö i sawé

kề i amì kư.'

Ie'pa déwa icha inúk, ie'pa démale icha ñe'e, tkệk ta ie'pa démale. hacia acá,

el lagarto les dice:

"Al cuarto día volveré"

"Entonces, pues, al cuarto día

serás llamado, pues,

a pasarme de nuevo

hasta aquí "

Al cuarto día vuelven.

Mientras ellos se fueron, entonces, mientras andaban allá, a la madre de los Sềrkës la devoró su padre.

FP: ¿El padre de losSềrkës ?

JP: Mm. A su hija... devoró a su hija.

El devoró a su joven hija.

Pues, cuando ellos se fueron, mientras aquellos sus hijos se ausentaron, él mató, pues, a su madre.

La devoró él, pues,

y metió la cabeza en una canastilla asi

arriba,

pues, allá arriba, en lo alto,

en una ménsula así arriba,

arriba sobre una repisa,

en la viga de corona de la casa cónica, pues.

FP: Mjm.

JP: Sobre la viga de corona, pues, la metió, pues, allí arriba.

FP: ¿La cabeza de quién metió?

JP: De aquella que devoró, de su hija que devoró, él metió la cabeza.

FP: ¿Pero quién la devoró?, perdón, ¿Sềrkë ?

JP: $\quad$ Su abu...su abu... su abuelo, su abuelo. E1 abuelo de los Sè̀rkës. ¿Comprendes?

FP: $\quad \mathrm{Ah}$, ¿ el abuelo de los Sèrrkës ?

JP Mjm. Ella era, pues, su madre, mira tú, a ella...

FP: ¿Devoró a la madre de los Sèrrkës?

JP: El devoró a la madre, devoró a su joven hija.

FP: Ah, ya. Ajá.

JP: Entonces los hijos vuelven $y$, pues, entonces los hijos ven que su madre no estaba.

Ellos llegan, pues, a jugar, regresan, pues, entonces, a los cuatro dias regresan. 


\section{Ie'pa démale,}

icha ie'pa kákồke,

ie'pa kákồke,

ie'pa kákồkẹ,

ie'pa kákồke inúk icha,

kàl wö ư' yök icha,

i wố ư' yök icha,

i wó ú yök...

145 FP: Di' ñalà biök.

JP: Di' ñalà biök,

di'...di' ñalà biök...

E' icha di' ñalà biök,

di' i...

ie'pa démale icha inúk kàl wö wa.

Ne'e icha ie'pa r kàl wö u'yéka

ia'ka

páka

wée i bika' tkër e' a.

Icha bika' a,

ta ñée i amì wóki tkër,

i amì wóki ârki bika' a

e' ujtéka i tá tö :

"Mika icha a' mìnêyar,

e' ta... e' ta icha... e' ta icha

ba dawö'chkeala r ye' kótwa"

E' wóki tkë'ka ie' dör bika' a,

wô... sa wôki dichéề ârkị.

FP: E' tạ... E' ta mì sè̀rképa dêne ta ¿ie'pa kề wa $\mathrm{i}$ ichàkìne tö wé ñi mì?

JP: Kề stséskua...

Sibồ... Sibồ r... Sibồ r... i én a...

FP: Sibồ $r$ i én a $i$ chôwếwa.

170 JP: Aû. Sibồ... Sibồ kề $\mathrm{r} i$ ichàkók ke.

Ne'e ie' tso' inúk e'..

i wốki ñe' r...

i a amì wóki tkër bika' a e'...

I cha ñe’e kàl wö u'yök ie' tso'

iềne’ka pá

e' tsứkka e'köl i míaka dör i sawé

ta awìk te... i amì wókir ârki

e' ujtéka i tá icha :

"Ba dawö'chkela r icha ye' kata'wa,
Ellos regresaron,

$y$, pues, viajaban,

viajaban,

viajaban,

viajaban a jugar, pues,

a lanzar la bola, pues,

a lanzar su bola, pues,

a lanzar su bola...

FP: A cavar cauces de ríos.

JP: A cavar cauces de ríos,

a cavar cauces de ríos...de ríos...

A eso, pues, a cavar cauces de ríos, ríos e...

ellos regresaron, pues, a jugar con la bola.

Entonces, pues, lanzan la bola,

se encestó

arriba, pá,

ahí donde estaba la canastilla.

$Y$, pues, en la canastilla,

estaba entonces la cabeza de su madre;

la cabeza de su madre que estaba en la

canastilla

habló con él:

"Cuando, pues, os fuisteis,

entonces... entonces, pues... entonces, pues, tu abuelo me mató".

De la cabeza que él había puesto en la canastilla,

la ca... calavera tan sólo estaba allí col-

gando.

FP: Y... Y, cuando regresaron los Sèrkës, ¿No preguntaron ellos

dónde estaba su madre?

JP: Parece que no...

Sibồ ... Sibồ ... Sibồ ... los...

FP: $\quad$ Sibồ los hizo olvidarse.

JP: No. Sibồ... Sibồ no permitió que indagaran.

Entonces, al que estaba jugando...

la cabeza aquella...

la cabeza de su madre que estaba en la

$$
\text { canastilla... }
$$

Pues, entonces la bola que estaba lanzando cayó alli arriba i pá!

y el que sube solo a traerla ve

que allá esta... estaba la cabeza de su madre, la cual le habla:

"Tu abuelito, pues, me devoró, 
180

185

190 icha mìka a' mìne

e' ké wa icha ye' kata'wa ie' tö."

Kề ie' wa ì yềne

icha ie' $r$ i iékamale

bềr $\underline{\mathrm{i}} \mathrm{e}^{\mathrm{e} . . .}$ ie' démale $\underline{\text { is. }}$

FP: ¿Ile’ bola ñe’ éwane?

JP: E' éwa ie'r.

Ie' $r$ i wóki né ujté ie' ta è̀..

ñe' è̀ stsé ie' $r$,

bềr ie' e' éwa.

Nè'e ie' dûrki,

ie'pa tso' inúk,

ie'pa tso' awík,

ie'pa tso' inúk

ie'pa tso' i... ie'pa tso' inứk.

Ne'e ie' $r$ i ché tö icha, ie'stsồ,

ñẹe icha i wébiala wé $r i$ kúwa,

e' stsồke icha ñe':

"Nawi a skà lèèè

nawi a skà lè,

nawì a skà lèèè

nawi a skà lè".

Kề i yàmi ulìtane én a i àne tö ì kué́ki ie' stsồke.

I sawé ie' r e'...e' r... e'...

i ujté ie' ta e'...

FP: I I tso' alà stsôunk...

JP: $\quad$ E' kuéki ie' tso' ...

ie' stsồke icha,

ie' tso' inúk icha:

"Awì a skà lèèè

awi a a skà lè,

awì a skà lèèè

awì a."

Dồka icha ie'pa mi'ttke ñe', ie' batà mi' dë' rë,

ñe' $r$ i batà mìne' yar,

ie'pa $\mathrm{r}$ dawö'chkeala ujtôwa

katówaat

wókir iókaat aìè,

wé i amì... i âmì ârkí,

wókir ârki e' dök.

Ie'pa mí chôë awì̀ é...

FP: ¿E' ta wé ie'pa mínèa rë?

JP: Ie'pa mí de awí cielo tkër, cuando os fuisteis, pues, ese mismo día me devoró él." El no dijo nada, pues, la volvió a poner $y$, en silencio, se... volvió abajo.

FP: ¿Apeó la bola?

JP: La apeó.

A la cabeza que le habló sólo... sólo la escuchó

y descendió en silencio.

Entonces, se estuvo parado, ellos estaban jugando, estaban por allá, estaban jugando, estaban ju... estaba jugando.

Entonces, dice,

canta él,

entonces, pues, el que la habia encontrado, canta, pues, entonces:

"En compensación nuevamente tal vez, en compensación nuevamente tal vez; en compensación nuevamente tal vez, en compensación nuevamente tal vez". Ninguno de sus familiares comprendió por qué cantaba

Lo que había visto, eso... eso era...eso... lo que le habia hablado, eso...

FP: Estaba haciendo cantar al muchacho...

JP: A causa de ello estaba...

cantaba, pues,

estaba jugando, pues:

"Hacia allá nuevamente tal vez, hacia allá nuevamente tal vez; hacia allá nuevamente tal vez, hacia allá."

Hasta, pues, que ya se iban para allá, el último que se iba,

aquellos que fueron los últimos en irse, ellos decidieron matar a su abuelito, decidieron dejarlo devorado, dejar la cabeza puesta allí arriba donde estaba su... su madre, alli donde estaba su cabeza. Y se encaminaron hacia allá.

FP: ¿Y adónde se fueron?

JP: Se van hasta allá donde está el cielo, 
e' âw íshet ie'pa mìne' rë.

A wi cielo... cielo tkër íes...

FP: Wé Sibồ r kéwe ie’pa yö' rö kó sạuk...

JP: $\quad$ Apàtkë kó sạuk

230

ta ie'pa r i sú

tö è kó r bua'...

FP: Ká $\mathrm{r}$ bua'è.

JP: Ie'pa mìne ùùù,

tkámi ñèe cielo et âwíshet.

235 Bueno, e' ie'pa tso' i' ta.

FP: Pero, ¿kó wé ké ska ñẹ' wà wámbalềnê?, FP: ñe' ie'pa....

JP: Kó i’ kí, kó i ki.

FP: I le dök.

JP: Kò̀ i ki i amì i a amì i amì i âmì

e' wốki kata' ie'pa r í dök.

Kó i ki i amì kata' ie'pa r, i dawö'chkeala kata' ie'pa $r$.

FP: Bueno, entonces ñe' sö i ché de

tö kó i' kị i dawö'chkeala kata' ie'pa dör, ¿i wîkeala también kata'nẹ kó i’ kị después?

JP: E' ie'pa mìne'a ñe'e

âwi dìwö dikì a ie' sè̀nuk ñée , cielo et âwíshet ie'pa mìne'a dồmale,

cielo et âwíshet ie'pa mìne’ a sènunk.

E' ñẹe ie'pa dör dabòñ éyök kí tèröl

e' shứ shàè̈,

se' $\mathrm{r}$ i kièke pàköl,

e' manètêmale icha.

Ie' $\mathrm{r}$ i chéat tö... i yám a tö:

"Ye' mía aìe dakë'ie icha ya talà sa .

Ya talà Bakùbulu kié icha, ya talà".

E'r icha i talà.

E' ché:

"É' ye' mía de icha, dakë'ie ye' mía de e " ".

FP: ¿E'r ì kie dakë'?

JP: Icha aláköl sa ie' míde

e' kie ie' r dakë'.

"E' icha ña mía de;
FP: ¿Qué es eso de pretendiente?

más allá se fueron.

Allá recto donde el cielo...el cielo está así.

FP: Adonde Sibồ primero los mandó a

conocer

JP: Los envió a conocer

y ellos vieron

que el lugar era bueno allá.

FP: $\quad$ El lugar era muy bueno.

JP: Se fueron ùùù,

atravesaron entonces hasta al otro lado del cielo.

Bueno, alli están en la actualidad.

Pero, ¿en qué lugar sucedió eso?, eso que ellos...

JP: $\quad$ En este lugar, en este lugar.

FP: Aquí.

JP: En este lugar a madre, su madre,

su madre

le devoraron la cabeza ellos.

En este lugar devoraron a su madre,

a su abuelito devoraron.

FP: Bueno, entonces en cuanto a eso que hemos dicho

que en este lugar devoraron a su abuelito, ¿devoraron a su abuelita también en este

lugar también después?

JP: Allá se fueron entonces

a vivir, entonces, allá debajo del sol,

al otro lado del cielo se

fueron de nuevo,

al otro lado del cielo se

fueron a vivir.

Alli, entonces, de ellos que son dieciséis, el de en medio,

lo que se dice el octavo,

ese regresó, pues.

Dejó dicho que... a sus parientes :

"Me voy allá arriba como pretendiente, pues, adonde mi abuelo paterno.

Adonde mi abuelo que se llama Bakùkulu, pues, mi abuelo."

Aquél era, pues, su abuelo.

Eso dijo:

"Para allá me voy, pues, como pretendiente me voy para allá."

JP: Pues, iba adonde una mujer, a eso llamaba él ser pretendiente.

"Para allá, pues, me voy; 
270

280

285

FP:

JP: Kabépa e'r kabépa e'.

\section{FP: A, ¿i pàkölël?}

JP: Mjḿ, e' ê yë'ttsa icha aláköl sạ.

Mjmí. E' ta e' r i chéât tö icha:

"Na mia icha aláköl sạ".

Töicha:

"Ya talà...ya talà Bakùbulu sa.

Ta icha kề ye' dë'mạle tkệk,

e' ta icha a' kié ya saúk,

e' ta icha ie'pa, ya bólökpa, r ya ujtéwa."

Chéat ie' $r$ yésyè̀së,

¿ì ie' a i chók?

Pues Sibồ $r$ ie' a i chéka tö :

"Ba bólök be" ujtèkệa".

Ie' déka Bakùbulu sa aìk,

ie' déka aláköl sạ.

Wè̀s kề ie' ulà dë aláköl să,

icha aìk kabépa tso',

icha itso' tso',

icha e' r ie' kótwa.

E'...e' kièke se' dawé...íma ...

ie'pa r uuu... dawéndepa.

FP: A, ¿ dawénde?

310 JP: Mjḿ, e'r kabépa. si a los cuatro días no vuelvo,

mis enemigos me habrán devorado, pues, mis enemigos me habrán matado, mis enemigos me habrán matado, entonces, pues, idme...

id a buscarme, pues.

Si a los cuatro días no vuelvo, id a buscarme, mis enemigos me habrán matado, pues." FP: Pero se vinieron ocho.

JP: No, uno solo.

FP: ¿Uno solo?

JP: Uno solo, el de en medio de la octena, ¿comprendes?

Cuatro, cuatro...

FP: ¿Qué solamente...a...?

JP: Cuatro y cuatro: ocho.

dieciséis eran ellos,

pero sólo el de en medio se separó para ir en busca de mujer.

El de en medio.

FP: Ah, ¿el octavo de ellos?

JP: Mjm, ese se separó, pues, en busca de mujer.

Mjm. Y él dejo dicho, pues:

"Me voy, pues, en busca de mujer."

Pues :

"Adonde mi abuelo...mi abuelo Bakùbulu.

$Y$, pues, si no he regresado al cuarto dia, id a buscarme, pues,

ellos, mis enemigos, me habrán matado, pues".

Lo dejó dicho tan precisamente.

¿Qué se lo revelaria?

Pues Sibồ se lo reveló:

"Tus enemigos te van a matar."

Llega él adonde Bakùbulu, allá arriba, llega él a buscar mujer.

No logró estar con ella, allá habia kabè̀s, pues, habia itso's, pues, que lo mataron, pues.

FP: ¿Quiénes se llaman kabè̀s?

JP: Loskabềs son esos kabè̀s.

A ellos... a ellos los llaman duen... este... ellos son e... duendes.

FP: Ah, ¿duendes?

JP: Mjm, esos son los kabè̀s. 
Itso', pues, e' r tulu ...tuluvièapa , tula e vieja ollorona.

E' tso' ie' apánuk

aìk ié dekà,

ta ie' $r$ ie' ujtéwa ñe’e.

Ne'e ie' r sa i' i yawa',

íse shà,

ie $\mathbf{r}$ i r̂ée,

kichàtkéka icha,

FP: Mjmí.

íse kichàtkéka ar bö’ tsáka ie' r.

Tkệk ta icha

diàe i wébala ñé bitéka e'köl i sauk tö :

“¿Wé sa' tsó ché manètéo ?

E', ¿wé e'?"

I $\mathrm{e}^{\prime}$ biték

dó è' tkö i talà wốrki kula' kị,

ché icha:

"Sa' tsó manètéa,

¿e' dé ba kí?"

Ché icha :

"I déka ya ki.

Erë icha kề ye' iármale icha, i bólökpa rör icha i kótwa."

ne'e se' dé tkër,

Ne'e icha itsq' irir ñẹ'e kabépa $r$ i che,

“Sa yawa' mo' ar bö’ tsok....",

e' che s-ia tö,

e' che se' kuka tö icha :

"¿IIók a' iêtên icha,

e' kề dör icha...

Chkồ mQ’ ar séjkë séjkë bö’ tsóko

séfkë alè s-ịa;

sa yàm $\mathbf{s}$-apàkèkẹ, dià,

e'...e' ... e' a yulö̀na."

JP: I IsQ' tso',

itso' tso' sa añéikök.

FP: Nẹ'e...

JP: Bueno, stsé

se' dé tkër,

ékër ñẹ’e se'r i sawé,

ta icha sa yawa' mo' ar,

sa kalồ mo' ar,

íse shà icha,
Los itso's, pues, son las tule...tuleviejas,

tuleviejas o lloronas.

Ellos estan esperándolo

allá donde llega,

y ellos lo matan, entonces.

Entonces un cuarto de su cuerpo, como esta parte,

lo cortan,

lo guindan,

lo ponen colgado sobre el fuego.

Al cuarto día, pues,

sube de allá abajo un hombre a averiguar:

“¿Dónde se extravió el primero al venir?

Ese, ¿dónde está?"

Sube él hasta donde su abuelo,

llega a sentarse frente al abuelo, en una

banca,

dice, pues:

"E1 primero de nosotros que vino, ¿llegó él a tu casa?"

Dice, pues:

"Llegó hasta mi casa.

Pero, pues, yo no me he manchado, pues, sus enemigos, pues, lo mataron."

Entonces, cuando llega a sentarse,

entonces, pues, las tuleviejas y los duendes dicen:

"El cuarto de persona que cuelga sobre el fuego... ",

esto lo dicen para él, esto lo dicen para que escuche, pues: "¿ Para qué os estáis parados, no es, pues...

la carne que cuelga sobre el fuego, toda, toda,

para cocinarla para él toda, para nuestro pariente que nos visita,aquél, para servírsela a... a... a ép"

FP: Mjm.

JP: Las tuleviejas están en eso, se ocupan de que 10 atiendan.

FP: Entonces...

JP: Bueno, los escucha el que llega a sentarse, entonces, después, ve que un cuarto de persona está colgado, una pierna de persona está colgada, como esta parte; 
bö' tsáka ie'pa r i mo'ko,

sâwé ie' $r$,

ñe'e ie' $r$ i che,

Bakùbulu a ie' $r$ i che tö icha :

"Ekkềkë icha,

à talà icha,

sa' kàbalémale,

e' ta icha sa' bitếka tkệk,

sa' dulề bulàna diàe

mìka sa' shkèna dulề tök,

e ta icha be' ké íe sa' kulé amulk."

Bakùbulu $\mathrm{r} i$ ché $\mathrm{i}$ a....

Bakùbulu én a $i$ àna

tö ie'pa $r$ ie'... ie'... ie' ujtèmi,

ie'.. ie' ujtèwami dö,

e' kuécki ie' i bikéitse,

ie' $r$ i ché tö icha :

Kề icha ye' iànẹmanemale,

icha i bólökpa iár

irir e' kuéki icha

kề wè̀s $i$ ànuk icha,

ềkềkë."

Nẹ'e ie' $r$ i stsé ta

tkệk ta

icha ká ñak bulárwaie tírìrìrì tì tírì̀ì

ká dakarò àna ta.

Ie'r i stsé

tö ñe' ta ie'pa bitéka.

FP: ¿Sềrkë bitếka?

JP: Ká wêrwa icha ê sarù

ta icha ká balồwa tawísh.

I cha Sèrrkë bitéwa,

icha bulárbulárule;

icha tsîrë i batà sanèè,

icha $e^{\prime}$ wa basù ka'tsenn,

wès ajkéköl,

ajkéköl ki shkè e'kapë,

éts sulû,

mìk e' tkèke sö ís ki,

ta i bulárke chiríj;

e' ka'tsęn icha ie' wa,

ie' tsîrala batà sanè e' wa. sobre el fuego la habían colgado,

vio él,

entonces dice,

a Bakùbulu le dice, pues:

"Bueno, pues,

oh abuelo, pues,

regresaremos,

dentro de cuatro días, pues, subiremos, nuestro dulề se oirá allá abajo, cuando amanezcamos bailando dulề , entonces, pues, debes poner nuestra banca aquí."

Bakùbulu le dijo...

Bakùbulu comprendió

que ellos 10... lo matarian,

lo... lo vendrían a matar,

por eso pensó,

dijo, pues:

"Pues yo no me he manchado con su

sangre,

sus enemigos, pues, son los que se mancharon

y por eso, pues,

no hay nada que yo pueda hacer, de acuerdo."

Entonces el escucha,

a los cuatro días,

que, pues, en los confines de la tierra

retumba tírìrirìì tírìrìì

a la hora en que cantan los gallos.

Escucha

que entonces ellos vienen subiendo.

FP: ¿Vienen subiendo los Sèrrkës?

JP: Apenas se habia visto, pues, aclarar un poco,

cuando, pues, el tiempo se tornaba oscuro.

Pues, ya vienen llegando losSèrrkës, pues, haciendo ruido en tropel;

$y$, pues, el menor, tan flacucho,

pues, trae asida una lanza

a manera de bastón de palo de cacique,

como andando con bastón de palo de

cacique

cuyo peso es mucho,

$y$, cuando lo clava en el suelo,

suena $i$ chirij!;

esto lleva, pues, asido él,

el pequeñito, el menor, el flaco. 
400
E' kề dë'wa wéshke, e' tkámi icha ù tsì a , ká bata tậ̂e ñè tsì a aíshet.

Ká bata ñẹ tké tkél ie' $r$, ta stséskua ká bata bútskệ siwa' kị.

FP: Ajá.

JP: Nẹe kabépa katà àmé icha,

íes Bakùbulu $\mathrm{r}$ icha i’ a a kula' améwa íes tkồtsa diàe, ômik i skà améwa tkồtsa diàe. E' ètökicha i kabépa dapâwe, ètökicha itso' dapâwe.

E' âwì kị ie'pa katà âmé,

ie’pa déka diàe

e' katà âmé ulà wa.

E' wồske icha, ské icha,

kabépa è amé e’ amé icha ie'pa ské wótịök.

Kề kề kề ulà dë' icha ie'pa ska.

Itso' r icha, i kalé icha, itso' $r$ icha, i kalé icha...

I ku’yèkẹalor saké icha itso’' r.

Kè̀ wò̀tîníne, wồtînína tsîrè̀me, icha kể wồtîníne shùtaí.

FP: Ajá.

JP: Sềrkëè̀t kula', kula' ki ie'pa dé tulur, e' wồtîniwé éköl tö, kè̀ wồtîníne shùtai, wồtînína tsîralaềme.

Kè̀ wồtîníne.

Ne'e ie' dör... ie'pa ñe'e, Sềrkë dör ñẹ’e kabépa ñẹ' kalôúwo,

ñe’e maúulur séjko, bíl i dó e', bíl i tso' éjkë. "i I tso' tso" bíl e' kalôúwa,
Este no entró, pasó, pues, hacia la parte de atrás de la casa, más hacia arriba de la parte posterior de aquel grandísimo cerro.

Cuatro veces golpea el cerro aquel y pareciera que el cerro se fuera a suspender en el aire.

FP: Ajá.

JP: Entonces el asiento de los duendes coloca, pues,

de este modo Bakùbulu, pues, lo coloca, coloca la banca así, hacia allá, y a la par pone otra hacia allá . Una, para agrupar a los duendes ; la otra, para agrupar a las tuleviejas. Frente a ellas, hacia acá, pone el asiento de ellos

de los que llegan de allá abajo; su asiento coloca así, aparte. A aquellos los mueven, pues, tiran hacia sí, pues, los duendes se ponen, se ponen, pues, a tirar de ellos con su magnetismo. No, no, no lo consiguieron. Las tuleviejas, pues, succionan, pues; las tuleviejas, pues, succionan, pues...

Tiran de ellos para absorberlos, pues, las tuleviejas.

No se movió, se movió tan sólo un poquito, prácticamente no se movió, pues.

FP: Ajá.

JP: La banca de losSềrkës, la banca en que llegaron a sentarse, la logra mover alguno, pero no se movió prácticamente, se movió tan sólo un poquito. No se movió. Entonces él...ellos, entonces, los Sềrkës, entonces, deciden agarrar a los duendes,

los atan a todos, a cuantos hay, a cuantos están, en su totalidad. " A cuantas tuleviejas haya, agarradlas, 
440

445

450

455

460

465

470 mạúwa séjjka !"

¡Maúwa séjkạ?'

Ne'e ie'r i stsé

tö stséskua ká bata ñẹ tkók, ie', ñé' i tsîrala tkáka aíshet, e' r.

Stséskua ù bútsúrke siwa' kị, stséskua ù butsèkéumi síwa' dör.

Nè'e ie' $r$ i ché tö icha :

"Ye' e' taùttso icha a' ia icha.

Ye' $r$ vaca amè $a^{\prime}$ ia

ye' $r$ chò amè a' ia.

Ye' $r$ icha datsi',

sa ká sawi ąmè a' ia icha.

Ye' $r$ a' ia íma...

kồchi amè ye' r ä' ia icha, e' tawóie icha."

FP: Ajá.

JP: “E' tawoóie icha."

Ie' r vaca ...

FP: ¿Yì che?

JP: Bakùbulu $r \mathrm{i}$ che.

FP: ¿E' ta ie' $r$ bulu'?

JP: Ie' $r$ bulu'. Tó, Bakùbulu $r$ bulu'.

Ie' $r$ icha,

ie' $\mathbf{r}$ icha kồchi amé,

ie' $r$ icha vaca muéwa amé,

ie' $r$ icha sawi'jkuö amé amé,

ie' $r$ icha chò kalôwé,

ie' tònottso,

e' ta ñẹe se'è wồ kề tsiríneia.

Ne'e siwa' bútska ètökichaè,

kòs ñé,

kòs ie'pa tso',

ñé mìtse mìtséwa,

mí mìn iu icha chôë

awì, siwa' ki icha,

alồlồlồlồlö̀wo icha.

Mí chô ie'pa wa katè,

saké katèwa ie'pa r.

FP: Ne'e...

JP: Wẹ̀s ie'...ie' r i êrala kata'wa,

e' kuéki e' sụ̂ë i saké katèke.

FP: E' ta ñé, ñé' i apàkö shamâmâa, ¿wè̀k ie' míá? atadlas a todas!

i Atadlas a todas!

Entonces él escucha

que parece que golpea aquel cerro

él, el pequeñito, el que pasó más hacia arriba, ése.

Parece que la casa se quiere elevar en el aire, parece que el viento quiere llevarse la casa.

Entonces dice, pues:

"Os pagaré mi precio, pues,

a vosotros, pues.

Os daré vacas,

os daré chompipes.

Ropas, pues,

mastates, os daré, pues.

Os este...

Os daré cerdos, pues, como pago por mí mismo, pues. "

FP: Ajá.

JP: “Como pago por mí mismo, pues." El vacas...

FP: ¿Quién dijo eso?

JP: Bakùbulu lo dijo.

FP: ¿Entonces él era rico?

E1 era rico. Sí, Bakùbulu era rico.

El, pues,

entrega, pues, cerdos,

ata y entrega, pues, vacas,

entrega y entrega, pues, telas,

coge, pues, chompipes,

paga su precio,

y, entonces, ya no lo acosan más.

Entonces, se elevó un tornado,

y a todo aquello,

a todos cuantos había, los arrastra, los arrastra, se van, van llorando, pues, allá en el viento, pues, sonando al entrechocar alölö̀lòlồlồwQ, pues.

Se los llevan para devorarlos, como retribución los devoran.

FP: Entonces...

JP: Tal y como ellos...ellos habian devorado a su hermanito, por ello y de modo semejante en retribución los devoran.

FP: Y aquél, aquél que era velludo, ¿por dónde se fue? 
JP: E' míatkemale,

e'r i sulú,

e' kề dồwa ta wésh,

e' míatke.

FP: A, ¿e' tso' i wókirie?

490 JP: E’r i wóki, i wơki kibí.

E' kalò̀ kùke é é íyi âamik íes,

e' $r$ kàl tkéttsaie icha irìrìrì.

FP: Juu...

JP: E'r i wơki kibí; e'ël sér sulûë icha, e'ël sếr sulûë icha.

FP: Pero, e' r i sanéala.

JP: $\quad$ E'r i batà sạnèè,

e' sér sulûë icha.

$E^{\prime}$ icha kòs ie'pa ñé....

kòs ie' mìnéa,

kès ñe',

kòs,

mìk e' míatke,

e' ta ñe'e, stséskua,

kówö wờkalônámale,

ká balö̀yâmale.

Itso' mìnètseñ ie'pa wa katè.

E' kuéki e' kàrkö tso' ie'pa wa.

I tso' katèke ie'pa r kékrá éjkë.

Kabépa katèke ie'pa r kékrá éjkë.

$E^{\prime}$ kè̀ sùne se' wa.

Kó bánêt, be' r i saúu,

kó bata a ia'chki se' tso'ia,

aìe tạ se' se' ù ậmik,

i' tsínet,

àsir tkáa ie'pa wa púj,

ùùù àsir yënàna.

Se' kề wa i ujchến tö ì kuévi ;

ñe'nma è ie'pa ề tiéwa se' se' aló wa.

Yéttsa ie'pa $r$.

FP: ¿Yì è tiéwa?

JP: Itso', kabépa.

E' balé tulur i' ta íe,

se' aló âmik, tsînet.

Á, e' ta ie' $r$ i sawé

tö ie' kề r se' kè.

Ya'ttsa ie'wa :

I kë. ¿Wé ñè ma è baló?
JP: Ése se fue ya de nuevo,

ése era el más fiero,

ése que no habia querido entrar, ése se fue ya.

FP: Ah, ¿estaba de caudillo?

JP: Era su caudillo, su gran caudillo. rozaba los pies en las cosas así, derribaba los árboles, pues, irìrì rì.

FP: Juu...

JP: Era su gran caudillo; se conducia con gran fiereza, pues, se conducía con gran fiereza, pues.

FP: Pero era el flaquillo.

JP: Era el menor, muy flaco, el que se conducía con gran fiereza, pues. Él, pues, todos ellos, aquellos... todos se fueron, todos aquellos, todos, $y$, cuando ya se fueron, entonces, parece, que el tiempo se calmó, que el tiempo se apaciguó.

A las tuleviejas se las llevaron para devorarlas.

Por ello tienen esa misión.

A las tuleviejas las devoran siempre asi. A los duendes los devoran siempre asi. Eso no lo vemos nosotros.

En otros lugares, mira tú, en los cerros, en otros tiempos, cuando todavía vivía gente alli, allá arriba a la par de las casas de las personas, de las personas,

en las proximidades de estas hacen que se venga un derrumbe púj, ùùu se desliza el derrumbe.

Las personas no saben por qué; la verdad es que alli se meten al amparo de las personas.

$Y$ los sacan.

FP: ¿Quién se mete?

JP: Las tuleviejas, los duendes.

Se están escondidos ahora aquí, al amparo de las personas, cerca.

$A h$, entonces ven

que a las personas no se las toca.

Los sacaban:

Toma. Escóndete, a ver. 
530

FP: Ajá.

JP: E' kie e'kapë.

\section{E'kapë.}

FP: Mjmí.

JP: Mjmí.

535 FP: ¿E'sề?

JP: Tóo, e'kapë.

I e’pa ie'pa ie'pa kalétë' Sibồ tö.

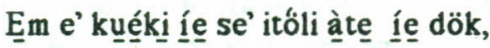

sìkua, se' se' se' siàrrala,

540

545

550 pero s-âñ ujtồwa ta aláköl kuévín.

Sì kua yì añî ujtồwaie aláköl kuékị.

E’r icha ie'pa bák ië’tẹn ká i kị,

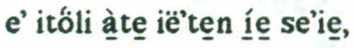

se' àtee,

sék se' àte,

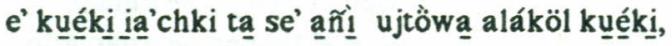

sìkua âni ujtồwa aláköl kuéki.

Ém e' r ie' kaléitö âmẹat Sibồ dör, súno se'a tö :

"Sú, i itôli tso'ia,

kè̀ i bákmi."

Ikë, e'kapë.
FP: Ajá.

JP: Así es la cosa

Así.

FP: Mjm.

JP: Mjm.

FP: ¿Así no más?

JP: Sí, así.

A ellos, a ellos, a ellos los conmemoró Sibồ.

Y, por ello, aquí... sus sucesores que hemos quedado aquí,

los blancos y nosotros, nosotros, nosotros pobrecitos,

nos matamos por las mujeres.

Algunos blancos se matan por las mujeres.

Ello fue, pues, que ellos estuvieron sobre este mundo,

y sus sucesores quedaron aquí como personas,

las personas que quedaron, todas las personas que quedaron;

$y$, por ello, antes se mataban las

personas por las mujeres

y los blancos se matan por las mujeres.

Y ello es que Sibồ dejó su ejemplo

para que lo veamos nosotros:

"Mirad, todavía hay herencia de ellos, no ha desaparecido."

Bien, asi es.

\section{Traducción literal}

1. FP: Bueno entonces aquello yo-erg ello dije(pro) este... 2. ¿cómo Sè̀rkë rec peleó(impro)... 3. o muchachos rec peleólimpro)? 4. ¿Cómo él sellamaba(imp2)...? 5. JP:¿Bakùbulu? 6. FP:Bakùbulu con. 7. Eso cuenta yo-a. 8. ¿cómo eso sucediólimpro)? 9. Eso ser pues primeramente, 10. cuando pues... u...11. cuando pues esos e... Sèrrkëesos nacieron(improl aquí. 12. Sềrkë nacieron(impro) aquí, 13. lugar este en Sè̀rkë nacieron(impro). 14. FP: Mjm. 15. JP: Sềrkë nacieron(improl pequeñitos aquí, 16. como niñitos, 17. personas hijitos, 18. fueron -encontrados(pro) así. 19. Con pues ellos barranca camino cavaron(pro), 20. pues río aquel camino cavaron(pro), 21. río aquel-abajo cavaron(pro),22. río aquel-arriba escarbaron(pro), 23. aquel-abajo, aquel-abajo, aquel-abajo escarbaron(pro), 24. excavó(pro) él erg, 25. ellos pequeños esos ser pues. 26. FP:Pero, ¿esos ser quién hijos? 27. JP: Pues esos...esos m... 28. FP: ¿O sólo esos creólpro) Sibồ erg? 29. JP: Esos creó(impro) Sibồ erg. 30.FP: Ajá. 31. JP: Sibồ erg esos creó(impro), 32. esos nombre mencionó(pro), 33. aspecto eso así ello-ser. Pues... 34. FP: ¿ Sërrkë? 35. JP: Sè̀rkë. 36. FP: Mjm. 37. JP: Eso con entonces pues esos erg cómo... personas... 38. esos erg lugar aquel lugar aquel cavaban(imp2), 39. lugar m... lugar camino este, 40. barranca camino cavaban(imp2), 41. barranca camino desgastaban (imp2) 42. como niñito pequeño pequeño 43. río río pequeñitos esos desgastan(imp1) asi. 44. Eso ser entonces 45. ellos llegaron(pro) grandecitos, 46 . con entonces ellos crecen(imp1)(lim), 47. con entonces ellos ser octena dos-conjuntos 48. -eso ser nosotros erg ello llamamos(imp1) que diez un-conjunto más seis-. 49 . 
Eso con su extremo flacolint)(dim) ese ser fierolint). 50 . Ese pierna vello tiene(imp1), 51 . ese pecho vello estar-colgando abundante(int). 52. FP: ¿Ese ser blanco hijo? 53. JP: Mjm.54. FP: Ajá.55. Eso con entonces pues 56. primero ellos fue(pro) envió(pro) Sibồ erg 57. lugar ver aquel debajo en pues. 58. FP: Ajá. 59. Sol debajo en pues él obligó(pro), 60. él envió(pro) Sibồ erg ; 61. Sibồ erg él envió(impro) aquel debajo en lugar ver: 62. '†Tú ve(opt) lugar ver 63. que cómo ello-ser! “64. FP: ¿Quién? ¿Aquellos? 65. Ello hombres aquellos. 66. FP: ¿ Todos? 67. JP: Esos enviólpro) todos Siböerg lugar ver 68. que "Id lugar ver 69. que cómo lugar ser"' 70. Ellos fueron(pro) ùùù 71 .llegaron(pro) mar aquel-abajo en 72. con mar ese... con hombre aquel estar-sentado pues... 73. FP: ¿Quién estar-sentado? 74. JP: Allí entonces lagarto estar-acostado pues, 75. ese llaman(imp1) pues tío-materno. 76. Ese a ello dijeron(pro) pues, 77. lagarto a ello dijeron(prol pues: 78. " Oh tio-materno pues, 79. nosotros vamos(pro) lugar ver, 80. yo-a pasa(opt) tú-erg balsa sobrë.81. FP: Ajá. 82. JP: Entonces pues ellos... 83. ellos balsa aquella 84. lagarto espalda sobre, 85 . ellos ref subieron(pro), 86. esos llevó(pro) lagarto ùùù , 87. dejó(prol agua al-otro-lado. 88. FP: ¿Ellos van(imp1) todos(lim)? 89. JP: Mjm, todos. 90. Cuando hacia-acá él anda(ya)(rep), 91. lagarto erg ello dijo(prol ellos a que: 92. "Al-cuarto-día yo llegolimpi)(rep)". 93. "Eso con pues al-cuarto-dia 94. tú habrás-sido-llamado(pro)(rep) pues 95. Yo pasar(rep) 96. llegolimp1)(rep) aquí." 97. Al-cuartodía él llegó(pro)(rep). 98. Eso mientras él fuelimpro), 99. cuando eso mientras entonces durante él andaba, 100. Sè̀rkë mamá(dim) devoró(impro) ella padre erg. 101. FP: ¿ Sërkë padre erg ? 102. JP: Mm. El hija... él hija devorólimpro). 103. Êl hija joven devoró(impro) él erg. 104. Pues cuando él fue(impro) wö... wö..., 105. ella hijos aquellos seausentaron(impro) eso mientras con, 106. ellos madre mató(impro) pues él erg. 107. Devorólimprol él erg pues, 108. cabeza metió(impro) él erg canastilla en asi-arriba, 109. pues alto aquel(arriba),110. palo armazón sobre así-arriba, 111. aquel-arriba grada sobre, 112 . casa punta en viga-de-corona sobre pues. 113. FP: Mjm. 114. Viga-de-corona sobre pues 115. él erg ella metió(impro) pues allá-arriba llegar.116. FP: ¿Quién cabeza metiólimpro)? 117. JP: Aquella ella devorólimpro), 118. él hija devoró(impro) él-erg,
119. esa cabeza metió(impro).120. FP: ¿Pero quién erg esa devoró(impro)?, 121.perdón, ¿ Sè̀rkë? 122. JP: ellos ancia...ellos ancia... ellos anciano(dim), ellos anciano(dim). 123. Sềrkë anciano(dim). ¿Cayó(pro) tú hígado en? 124. FP: Ah, ¿ Sềrkè abuelo? 125. JP: Mjm. Esa ser pues ellos madre, 126. tú ello velopt), ella a... 127. FP: ¿ Sềrkë madre devorólimpro)? 128. Madre devorólimprol, 129. él hija joven devoró(impro) él erg. 130. FP: Ah, ya. Ajá. 131. JP: Entonces ella hijos aquellos volvieron(pro)(rep) 132. con pues entonces ella hijos erg ello vieron(pro) 133. no ellos madre no-estar. 134. Ellos llegaron(pro) pues jugar, 135. Ellos llegaron(pro)(rep) pues entonces, 136. a-los-cuatro-dias ellos llegaron(pro)(rep). 137. Ellos llegaron(pro)(rep), 138. pues ellos viajaban(imp2), 139. ellos viajaban(imp2), 140. ellos viajaban(imp2), 141. ellos viajaban(imp2)jugar pues, 142. árbol fruto lanzar pues, 143. ellos fruto lanzar pues, 144. ellos fruto lanzar... 145. FP: Río camino cavar.146. JP: Río camino cavar, 147. río...río camino cavar... 148. Eso pues río camino cavar, 149. río e... 150. Ellos llegaron(pro)(rep) pues jugar árbol fruto con. 151. Entonces pues ellos erg árbol fruto lanzaron(pro), 152. se-encestólimpro), 153. pá-arriba 154. dónde ella canastilla estar-puesta eso en. 155 . Pues canastilla en, 156. con entonces ellos madre cabeza estar-puesta, 157. ellos madre cabeza estarcolgando canastilla en, 158. esa habló(pro) él con que: 159. "Cuando pues vosotros fuisteis(impro), 160. eso con... eso con pues... eso con pues 161. tú abuelomaterno(dim) erg yo mató(impro). "162. Esa cabeza metiólimpro) él erg canastilla en, 163. cabe...persona cabeza hueso(lim) estar-colgando. 164. FP: Eso con...Eso con cuando Sèrrés llegaron(impro)(rep), 165. con ¿ellos no ag ello preguntaron(perf) que 166. dónde yo madre? 167. JP: No se-siente-personapara...168. Sibö̀... Sibồ erg... Sibồ erg... ellos hígado en... 169. FP: Sibồ erg ellos hígado en ello hizoperder(pro). 170. JP: No. Sibồ... Sibồ no erg ello preguntar permitió. 171. Entonces él estaba(imp1) jugando ese... 172. ella cabeza aquella erg... 173. él madre cabeza está-puesta canastilla en esa... 174. Pues entonces árbol fruto lanzando él estába(imp1) 175. fue-echada(impro) pá 176. ref subir uno él fue (pro) erg ello vio(pro) 177. con por-allá te... él madre cabeza estaba-colgando 178. esa habló(pro) él con pues: 179. "Tú abuelo-maternoldim) erg pues yo devoró(impro),180. pues cuando vosotros 
fuisteislimpro) 181. eso tiempo con pues yo devoró él erg."182. No él ag qué dijo(perf) 183. pues él erg ella echó(pro)(rep) 184. en-silencio él ref... él llegó(pro)(rep) suelo. 185. FP: ¿Él bola aquella apeó(pro)(rep)? 186. JP: Esa apeólpro) él erg. 187. É1 erg ella cabeza aquella hablólpro) él con(lim)... 188. aquella(lim) escuchólpro) él erg, 189. en-silencio él ref apeó(pro). 190. Entonces él estar-de-pie, 191. ellos estaban(imp 1) jugando, 192. ellos estaban(imp1) por allá, 193. ellos estaban(imp1) jugando, 194. ellos estaban(imp1) i... ellos estaban(imp1) jugando. 195. Entonces él erg ello dijo(pro) que pues, 196. él cantaba(imp1), 197. entonces pues ello hombre cuál erg ella encontró(impro), 198. ese cantaba(imp2) pues entonces: 199. "Deuda para nuevamente tal-vez 200. deuda para nuevamente tal-vez,201. deuda para nuevamente tal-vez 202. deuda para nuevamente tal-vez". 203. No él pariente todos hígado en ello cayólimpro) 204. que qué por él cantaba (imp2). 205.

Ello violpro)él erg eso...eso erg... eso...206. ello habló(pro) él con eso... 207. FP: Ello estaba(impl) muchacho haciendo-cantar... 208. JP: Eso por él estaba (imp1)... 209. él cantaba(imp2) pues, 210. él estaba (imp1) jugando pues: 211. "Aquello para nuevamente tal-vez 212 . aquello para nuevamente tal-vez, 213. aquello para nuevamente tal-vez 214. aquello para." 215 . Llegaba (imp1) pues ellos iban(imp1)(ya) aquel, 216. ćl extrcmo iba (imp1) llego (impro), 217. aquellos son ellos extremo fueron(impro),218. ellos erg abuelo-materno (dim) mataron (opt), 219. dejaron-devoradolopt) 220. cabeza dejaron-echada (opt) allá-arriba, 221. dónde ellos madre...ellos madre estar-colgando, 222. cabeza estar-colgando allí llegar. 223. Ellos fueron(pro) rumbo-definido allá... 224. FP: ¿Eso con dónde ellos fueron(impro) llegaron(improl? 225. JP: Ellos fueron(pro) llegaron(pro) aquel cielo estarpuesto, 226. eso más-allá cllos fueron(impro) llegaron(impro). 227. Aquel cielo ... cielo estarpuesto así.228. FP: Dónde Sibồ erg primero ellos hizo (impro) llegan(imp1)lugar ver...229. JP: Enviólimpro) lugar conocer 230. con ellos erg ello vicron(impro) 231. que alli lugar ser bueno... 232. FP: Lugar ser bueno(int). 233. JP: Ellos fueron(impro) ùùù, 234. pasaron(pro)entoncescielo otro-lado-de más-allá. 235. Bueno, alli ellos cstán(imp1) esto con. 236. FP: Pero, ¿lugar cuál ticmpo durante aquello contenido sucedió(impro)? 237. aquello cllos... 238. JP: Lugar este sobre, lugar este sobre. 239. FP: Aquí llegar. 240. JP: Lugar este sobre ellos madre ellos madre ellos madre 241. esa cabeza devoraron(improl ellos erg aquí llegar. 242. Lugar cste sobre ellos madre devoraron(improl ellos erg, 243. ellos abuelomaterno(dim) devoraron(impro) ellos erg. 244. FP: Bueno, entonces aquello nosotros-crg ello dijimos(prol llegamos(pro) 245. que lugar este sobre ellos abuelo-maternoldim) devoraron(impro) ellos erg, 246. ¿ellos abuela-materna(dim) también devoraron(impro)(rep) lugar este sobre después ? 247. JP: Allá ellos fueron(impro) entonces 248 . aquel sol debajo en él vivir entonces, 249 cielo otro-ladode más-allá ellos fueron(impro) llegan(imp1)(rep), 250.cielo otro-lado-de más-allá ellos fueron(impro) vivir. 251. Alli entonces ellos ser diez un-conjunto más seis, 252. eso interior en-mediolint), 253. nosotros erg ello llamamos(imp2) ccho, 254. ese vino(pro)(rep) pues. 255. Él erg dejó-dicho(pro) que... él pariente a que: 256. "Yo voy(pro) allá-arriba pretendiente-como pues yo abuelo-paterno donde. 257. Yo abuelo-paterno Bakùbulu se-llamalimp1) pues, yo abuelo-paterno". 258. Ese ser pues él abuelo. 259. Eso dijo(pro): 260."Allá yo (pro)voy llegolprol pues, 261. pretendiente-como yo voy(pro) llego(pro) allá.'262. FP: ¿Eso ser qué se-llama(imp1) pretendiente? 263. JP: Pues mujer donde él fuc(pro) llegó(pro) 264. eso llama(imp1) él erg pretendiente. 265. "Allá pues yo voy(pro) llego(pro); 266. eso con alos-cuatro-dias no yo llegué(perf)(rep), 267. eso con pues yo enemigos erg yo devorólpro), 268. yo enemigos erg yo mató(pro), 269. yo encmigos erg yo mató, 270. eso con pues vosotros iréis( pro) yo... 271. vosotros iréis yover pues. 272. A-los-cuatro-dias no yollegué(perf)(rep), 273. eso con vosotros iréis(pro) yo ver, 274. eso con pues yo enemigos erg yo matólprol.' 275. FP: Pero ellos vinieron(pro) ocho. 276. JP: No, uno(lim).277. FP: ¿Uno(lim)?278. JP: Uno(lim), octena esa interior en-medio, 279. ¿cayó(pro) tú hígado en? 280. Cuatro, cuatro... 281. FP: ¿Qué(lim) erg...a...? 282. JP: Cuatro más cuatro: ocho. 283. Dieciséis cllos ser, 284 pero ellos interior medio-en cse(lim) ref separó(impro) pues mujer donde. 285. Interior medio en(lim) como-ese. 286. FP: Ah, ¿ellos octavo? 287. JP: Mjm, ese ref separó(impro), pues mujer donde.. 288. Mjm. Eso con ese cllo dejó-dicho(pro) que pues: 289.'Yo voy(pro) pues mujer donde." 290. Que pues: 291. "Yo abuclo- 
paterno... yo abuelo-paterno Bakùbulu donde. 292. Con pues no yo llegué(perf(rep) a-los-cuatro-días, 293. eso con vosotros iréis(pro) yo ver, 294. eso con pues ellos, yo enemigos, erg yo mató(pro). “ 295. Dejó-dicho(pro) él erg precisamente(int), 296. ¿qué erg él a ello decir? 297. Pues Sibồ erg él a reveló(pro) que: 298. "Tú enemigo tú matará(imp2)." 299. E1 llegó(pro) Bakùbulu donde allá-arriba, 300. él llegó(pro) mujer donde. 301. Cómo no él mano llegó(impro) mujer donde, 302. pues allá-arriba muchachos estaban(imp1), 303. pues itso' estaban(imp1), 304. pues esos erg él mataron(impro). 305. FP: ¿Quién se-llama(imp1) kabềs ? 306. JP: Kabềs esos ser kabềs esos. 307. Esos...esos llamamos(imp2) nosotros erg due...cómo...308. ellos ser uuu...duendes. 309. FP: Ah, ¿duende? 310. JP: $\mathrm{Mjm}$, esos ser kabề s. 311. Itso',pues, esos ser tule...tuleviejas 312. tula e vieja ollorona 313. Esos estaban(imp1) él esperando 314 . por-allá élllegó(pro), 315 . con él erg él mató(pro) entonces. 316 . Entonces él erg persona esta ella pedazo, 317. como-ésta enmedio, 318. él erg ello cortó(pro), 319. guindó(pro) pues, 320. como-ésta guindó(pro) estar-colgando fuego sobre él erg. 321. Al-cuarto-día con pues 322. allá-abajo ello hombre aquel subió(pro) uno ello ver que: 323. "¿Dónde nosotros primero seperdió(impro) vino(impro)? 324. Ése, ¿dónde ése?“ 325 .Él subió(pro) ùùù llegó(pro) él abuelo donde, 326. llegó(pro) ref sienta(imp1) él abuelo frente-a banca sobre, 327. dijo(pro) pues:328.“Nosotros primero vino(impro), 329. ¿él llegó(improl tú sobre?” 330. Dijo(pro) pues: 331. "E1 llególimprol yo sobre. 332. Pero pues no yo me-mancholimp1)(rep) pues, 333. él enemigos erg pues él mató(impro)." 334. Entonces persona llegó(pro) estar-sentado, 335. entonces pues tuleviejas y entonces duendes erg ello dijeron(pro): 336. "Persona cuarto atado estar-colgando fuego sobre...", 337. eso dijeron(pro) persona-para que, 338. eso dijeron(pro) persona para que pues: 339 . “¿Para-qué vosotros estar-parados pues, 340. eso no ser pues... 341. Comida atada estar-colgando toda toda fuego sobre 342 . toda cocinar(fin) persona-para; 343. nosotros pariente nosotros visita(imp2), aquélabajo, 344. ése... ése... ése para ser-servido(pro)." 345. FP: Mjm. 346. JP: Tuleviejas estaban(imp1), 347. tuleviejas estaban(imp1) persona haciendoatender. 348. FP: Entonces... 349. JP: Bueno, escuchó(pro), 350. persona llegó(pro) estar-sentado,
351. después entonces persona erg ello vio(pro), 352. con pues persona cuarto atado estar-colgando, 353 . persona pierna estar-colgando, 354. como-ésto enmedio pues, 355 . fuego sobre ellos erg ello colgaron, 356. vio(pro) él erg, 357. entonces él erg ello dijo(pro), 358. Bakùbulu a él erg ello dijo(pro) que pues: 359. "Bueno pues, 360. oh abuelo-paterno pues, 361. nosotros regresaremos(pro)(rep), 362 . eso con pues nosotros subiremos(pro) dentro-de-cuatro-días, 363. nosotros dulề sonará(pro) allá-abajo 364 . cuando nosotros amanezcamos(pro) dulề bailando, 365. eso con pues tú deberás(pro) aquí nosotros banca poner. " 366 . Bakùbulu erg ello dijolprol él a... 367. Bakùbulu hígado en ello cayólpro) 368. que ellos erg él él él matarian(pot), 369. él él matarian(pot) llegan(imp1), 370. eso por él ello pensólpro), 371.él erg ello dijo(pro) que pues: 372 . 'No pues yo memanché(impro), 373. pues él enemigos semancha(imp1) 374. y eso por pues 375 . no cómo ello caer pues, 376 . bueno." 377 . Entonces él erg ello escuchó(pro) con, 378. a-los-cuatro-dias con 379. pues lugar límite retumbaba-seguidamente(imp1) tírìrìrìr tírìrìrì 80 . tiempo gallo cantó(pro) con. 381. Él erg ello escuchó(pro) 382. que aquello con ellos subieron(pro). 383. FP: ¿Sè̀rkë subieron(pro)? 384. JP: Lugar se-veía(imp1) pues apenas claro 385. con pues lugar se-oscurece tawísh. 386. Pues'Sềrkë acabaron-de-llegar(pro), 387. pues han-sonado-ysonado; 388. pues pequeñolint) ellos extremo flaco(int), 389. pues ése ag lanza lleva-asida, 390. como bastón. 391. Bastón con caminar(fin) asi, 392 . peso mucho, 393. cuando eso clavaba(imp2) persona-erg suelo sobre, 394 . con ello sonabalimp2) chiríj; 395. eso lleva-asido pues él ag, 396. él pequeño(dim) extremo flaco ese ag. 397. Ese no llególperf) adentro, 398. ése pasó(pro) pues casa parte-posterior en, 399. lugar extremo grande(int) aquél parte-posterior en más-arriba. 400. Lugar extremo aquel clavó cuatro él erg, 401. con sesiente-persona-para 402. lugar extremo se-suspendía(imp2) aire sobre. 403. FP: Ajá. 404. JP: Entoncer duendes apoyo puso(prol pues, 405. así Bakùbulu erg pues ellos para puso(pro), 406. banca puso(pro) así pasaba(imp1) allá-abajo, 407. a-la-par ello además puso(pro) pasalimp1) allá-abajo. 408. Eso una-vez él duendes agruparffin), 409. una-vez tuleviejas agrupar(fin). 410. Eso aquél sobre ellos a poyo puso(pro), 411. ellos llegan(pro) allá-abajo 412. 
esos apoyo puso(prol mano con.413. Esos movió(pro) pues, 414. tiró(pro) pues, 415. duendes ref pusieron(pro) ref pusieron(pro) pues 416. ellos atracción hacer.417. No no no mano llegó(perf) pues ellos hasta. 418. Tuleviejas erg pues, 419. succionaron(pro) pues; 420. tuleviejas erg pues, 421. succionaron(pro) pues... 422. Ellos chuparían (imp2) tiraron(pro) pues tuleviejas erg. 423. No semovió(perf), 424. se-movió(pro) poco(lim), 425. pues no se-movió(perf) prácticamente. 426. FP: Ajá.427. JP: Sè̀rkë banca, 428. banca sobre ellos llegaron(pro) estar-sentados, 429. esa hizo-moverse(pro) uno erg, 430. no se-movió(perf) prácticamente, 431. semovió(pro) pocoldim)(lim). 432. No se-movió(perf). 433. Entonces él erg... ellos entonces, 434. Sërkë erg entonces duendes aquellos agarraron(opt), 435. entonces ataron(opt) todos, 436. cuantos ellos vinieron(pro) esos, 437. cuantos ellos estaban(imp1) esa-cantidad. 438. Tulevieja estaba cuanta 439. agarraron(opt), 440. ataron(opt) toda, 441. ataron(opt) toda. 442. Entonces él erg ello escuchó(pro) 443. que se-siente-persona-para lugar extremo aquel clavar, 444. él, aquél ellos pequeño(dim) pasó-subiendo(pro) más-arriba, ése ser. 445 . Se-siente-persona-para casa se-elevará(imp2) aire sobre, 446 . se-sientepersona-para casa elevará viento erg. 447. Entonces él erg ello dijo(pro) que pues: 448. "Yo ref compro(imp1) pues, 449. vosotros a pues. 450. Yo erg vaca doy(imp1) vosotros a, 451 . yo erg chompipe doy(imp1) vosotros a. 452 . Yo erg pues ropa, 453. nosotros lugar tela doy(imp1) vosotros a pues. 454 . Yo erg vosotros a cómo... 455. cerdo doy(imp1) yo erg vosotros a pues, 456. ref pagar(fin) pueš.457. FP: Ajá. 458. JP: “ ref pagar(fin) pues." 459. El erg vaca ... 460. FP: ¿Quién erg ello dijo(pro)? 461. JP: Bakùbulu erg ello dijo(pro). 462. FP: ¿Eso con él ser rico? 463. JP: El ser rico. Si, Bakùbulu ser rico. 464. Él erg pues, 465. él erg pues cerdo dio(pro), 466. él erg pues vaca ató(pro) dio(pro), 467. él erg pues tela dio(pro) dio(pro), 468. él erg pues chompipe cogió(pro), 469. él se-comprólpro), 470. eso con entonces persona(lim) rostro no se-molestó(perf)(ya), 471. Entonces viento se-elevó una-vez(lim), 472. todo aquello, 473. todos ellos estaban(imp1), 474. aquellos lleva lleva, 475. se-van van lloran(imp1) pues con-rumbo-determinado(int) 476. allá, viento sobre pues, 477 . alồlồlồlồlồwo pues. 478. Llevaron(pro) con-rumbo-determinado ellos ag devorar(fin), 479. en-retribución devoran(imp1) ellos erg. 480. FP: Entonces... 481. JP: Como él...él erg ellos hermano(dim) devoraron(impro), 482. eso por eso semejante(int) él retribución devoran(imp2). 483. FP: Eso con aquél, aquél él cuerpo vello abundante, 484. ¿por-dónde él fue(pro)? 485. JP: Ese fuelpro)(ya)(rep), 486. ése ser ellos fiero, 487. ése no llega(imp1) tiene adentro, 488 . ése fue(pro)(ya). 489. Ah, ¿ése estaba(imp1) ellos cabeza-como? 490. Ese ser ellos cabeza, ellos cabeza mayor. 491. Ese pie arrastraba(imp2) por-su propia voluntad cosa a-lapar así, 492. ése erg árbol derribó pues irìrìrì 493. FP: Juu...494. JP: Ese ser ellos cabeza mayor. 495. ése vivia(imp1) fieramente(int)pues, 496. ése vivia(imp1) fieramente(int)pues. 497. FP: Pero, ése ser ellos flaco(dim).498. JP: Ése ser su extremo flaco(int), 499. ése vivia(imp1) fieramente(int) pues. 500. Ese pues todos ellos aquellos... 501. todos él fuelimpro), 502. todos aquellos, 503. todos, 504. cuando ése fue(pro)(ya), 505. eso con entonces, sesiente-persona-para, 506. tiempo secalmó(pro)(rep), 507. tiempo se-apaciguólrep). 508. Tuleviejas llevaron(impro) ellos ag devorar(fin). 509 . Eso por esecargo tienen(imp1) ellos ag. 510. Tuleviejas comen(imp2) ellos erg siempre así.511. Duendes comen(imp2) ellos erg siempre así. 512. Eso no vimos(perf) nosotros ag. 513. Lugar otro, tú erg ello velopt), 514. Lugar extremo en antes persona había(imp1)(todavía), 515. allá-arriba con persona persona casa a-la-par, 516. éstas cerca, 517. derrumbe hicieron-pasar(pro) ellos ag púj, 518. ùùù derrumbe se-deslizó(pro).519. Persona no ag ello sabelimp1) que qué por; 520. la-verdad-es-que allí ellos ref metieron(pro) persona persona amparo con. 521. Sacó(pro) ellos erg. 522. FP: ¿Quién ref metió(pro)? 523. JP: Tuleviejas, duendes. 524. Ref escondió estar-sentados esto con aquí 525. persona amparo a-la-par, cerca. 526. Ah, eso con él erg ello vidprol 527. que él no erg persona tocalimp1). 528. Sacó él ag: 529. Toma. ¿ dónde aquél tú ref esconde(opt)? 530.FP: Ajá.531. JP:Eso se-llama(imp1) así.532. Así. 533. FP:Mjm. 534. JP: Mjm.535. FP:¿Así(lim)? 536. JP: Sí, así. 537. Ellos ellos ellos conmemorólimpro) Sibồ erg. 538. Y eso por aquí persona descendencia queda(imp1) aquí llegar, 539. blancos, nosotros nosotros nosotros pobres(dim), 540.pero nosotrosrec matamos(imp1) con mujer por. 541. Blancos quién rec matan-frecuentemente(imp1) mujer por. 
542. Eso fue pues ellos estuvieron(impro) de-pie lugar este sobre, 543. esos descendencia queda(imp1) de-pie aquí personas-como, 544. persona queda(imp1), 545. toda persona queda(imp1), 546. eso por antes con persona rec matabalimp1)mujer por, 547. blanco rec mata(imp1)mujer por. 548. Y eso es él ejemplo dejó(impro) Sibồ erg, 549. ser-visto(fin) nosotros para:550."Mirad, ellos restos hay(todavía), 551. no ello pasólimpro)."552. Toma, así.

\section{BIBLIOGRAFIA}

Alexander, Hartley Burr. 1964a. The Mythology of All Races. Vol. X: North American . Cooper Square Publishers : Nueva York.

1964b The Mythology of All Races. Vol. $X I$ : Latin American . Cooper Square Publishers : Nueva York.

Bozzoli, María Eugenia. 1979. El nacimiento y la muerte entre los bribris. Editorial Universidad de Costa Rica: Ciudad Universitaria Rodrigo Facio, San José.

1983 “De Donde el Sol Nace a Donde el Sol se Pone: Mitología Talamanqueña del Clima y de las Enfermedades." América Indígena 13 (1).

Bray, Warwick. 1984. "Across the Darien Gap: A Colombian View of Isthmian Archaeology". En: Lange, Frederick W. y Doris Stone (compiladores) The Archaeology of Lower Central America. University of New Mexico Press: Albuquerque.

Cohen, Jean. 1974. Estructura del lenguaje poético Editorial Gredos: Madrid.

Eliade, Mircea. 1976. Myths, dreams and mysteries Collins Clear-Type Press : Londres y Glasgow.
Fernández Guardia, Ricardo. 1975. El descubrimiento y la conquista. Editorial Costa Rica : San José.

Guevara, Marcos. 1986."Mythologie des Indiens Talamanca (Costa Rica)". Tesis doctoral, Universidad de París X, Nanterre.

Lázaro Carreter, Fernando. 1962. Diccionario de términos lingüísticos y filológicos. Editorial Gredos: Madrid.

Margery Peña, Enrique. 1982.Diccionario fraseológico bribri-español, español-bribri. Editorial de la Universidad de Costa Rica, San José.

1989."La leyenda de La madre del Sol y de la Luna en una versión guaymí y en una versión del bocotá de Chiriquí". Ponencia presentada en el VII Simposio de la Asociación de Literaturas Indígenas Latinoamericanas. Albuquerque, Nuevo México.

Noss, Phillip A. 1972. "Description in Gbaya Literary Art". En: Richard M. Dorson (compilador) African Folklore. Doubleday \& Company Inc.: Garden City, Nueva York.

Pereira Mora, Francisco. 1983. "Narraciones de Francisco Pereira". Tradición oral indígena costarricense 1 (3).

Popol Vuh. 1965.Popol Vuh. Las Antiguas historias del Quiché. Traducidas del texto original con introducción y notas por Adrián Recinos. Fondo de Cultura Económica : México, Buenos Aires.

Preuss, Mary. 1988. Gods of the Popol Vuh . Labyrinthos : Culver City, California.

Schlabach, Raymond y Stephen Levinsohn. 1982 "Some Aspects of the Bribri Verb". Estudios de Lingüística Chibcha 1. 
Schultze-Jena, Leonhart. 1977. Cuentos y leyendas de los pipiles de Itzalco. Ediciones Cuscatlán : San Salvador.

Skinner, Alanson. 1920. "Notes on the Bribri of Costa Rica". Indian Notes and Monographs 7
(3). Museum of the American Indian Heye Foundation : Nueva York.

Stone, Doris. 1976. Arqueología de la América Central. Editorial Piedra Santa : Guatemala. 